\title{
II. Die Krystallformen und die gegenseitigen krystallographischen Beziehungen der Ephedrin-, Damascenin- und Aconitingruppe.
}

\author{
Von
}

K. Schwantke in Berlin.

(Mit 14 Textfiguren.)

\section{Inhaltsverzeichnis.}

Einleitung . . . . . . . . . ............ . 74

Das Ephedrin und seine Verbindungen . . . . . . . . . . . . . . . . . 74

Pseudoephedrin, natürliche Base . . . . . . . . . . . . . . 75

Umgelagertes Pseudoephedrin. . . . . . . . . . . . . . . . . 77

Ephedrinhydrojodid . . . . . . . . . . . $\quad 78$

Pseudoephedrinhydrojodid . . . . . . . . . . . . 80

Melhylephedrinmethyljodid . . . . . . . . . . . . . . . 81

Methylpseudoephedrinmethyljodid . . . . . . . . . . . $\quad 83$

Die Vergleichung der krystallographischen Verhältnisse . . . . . 83

Das Damascenin, das umgelagerte Damascenin und ihre Chlor-, Brom- und

Jodwasserstoffsalze . . . . . . . . . . . 84

Damasceninhydrochlorld . . . . . . . . . . . . 85

Damasceninhydrobromid ... . . . . . . . . . . . . 87

Damasceninhydrojodid. . . . . . . . . . . . . . . . . . 89

Umgelagertes Damascenin. . . . . . . . . . . . . . . . . 91

Hydrochlorid des umgelagerten Damascenins . . . . . . . . . . .. 93

Hydrobromid des umgelagerten Damascenins. .. . . . . . . . . . 94

Hydrojodid des umgelagerten Damascenins. . . . . . . . . . . . 97

Die krystallographischen Beziehungen innerhalb der Damasceningruppe 99

Das Aconitin und seine Verbindungen . . . . . . . . . . . . . . . 101

Aconitin, dargestellt von Schulze ........... 102

Aconitin, dargestellt von Dunstan ............ 103

Aconitin, dargestellt von Freund und Beck. . . . . . . . . 104

Aconitinhydrobromid ................. . . 105

Aconitinhydrochlorid. . . . . . . . . . . 106 


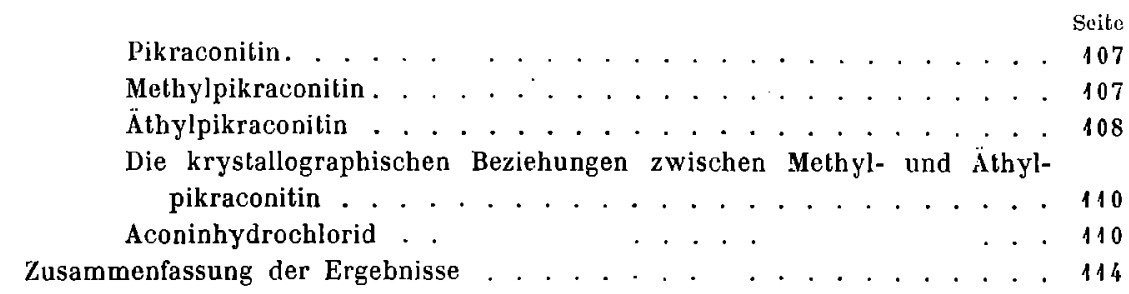

Das Material zur vorliegenden Arbeit erhielt der Verf. von dem Director des pharmaceutischen Instituts der Universität Marburg Herrn Geheimen Regierungsrat Professor Dr. E. Schmidt sowie den Herren Dr. H. Emde und Dr. Keller und von Herrn Privatdocenten Dr. H. Schulze in Erlangen. Die Untersuchungen, deren Ergebnisse in der Arbeit niedergelegt sind, wurden im mineralogischen Institute der Universität Marburg unter Anleitung des Herrn Geheimen Regierungsrats Professor Dr. M. Bauer und seines Assistenten, Herrn Privatdocenten Dr. A. Schwantke ausgeführt.

Ich nehme Gelegenheit, den erstgenannten Herren für die Freundlichkeit zu danken, mit der sie sich zur Überlassung des zum Teil kostbaren Materials bereit erklärt haben und meinen Wünschen, betreffend die Darstellung einzelner Salze, deren Untersucbung für die Gegenüberstellung der Glieder der verschiedenen Gruppen von Interesse war, entgegengekommen'sind.

$\mathrm{Zu}$ besonderem Danke bin ich Herrn Geheimrat Prof. Dr. M. Bauer und Herrn Privatdocenten Dr. A. Schwantke verpflichtet, deren stetem Wohlwollen und gütiger Unterstützung ich die Entstehung und Vollendung der vorliegenden Arbeit in erster Linie verdanke.

\section{Das Ephedrin und seine Verbindungen.}

In den Pflanzen der Ephedraarten kommen zwei isomere Alkaloide vor, von denen das eine zuerst von Nagai1) dargestellt und mit dem Namen Ephedrin belegt wurde. Seiner chemischen Zusammensetzung nach kommt ihm die Formel zu:

$$
\begin{gathered}
\mathrm{C}_{10} \mathrm{H}_{15} \mathrm{NO}=\mathrm{C}_{6} \mathrm{H}_{5}-\mathrm{CH}_{2}-\mathrm{CH}-\mathrm{CH}_{2}-\mathrm{OH} . \\
\mathrm{N}<\mathrm{CH}_{3}
\end{gathered}
$$

Später stellte E. Merck $\left.{ }^{2}\right)$ Ephedrin mit dem Schmelzpunkte von $40^{\circ}$ aus Ephedra vulgaris var. helvetica dar, während E. R. Miller ${ }^{3}$ ) daraus im Gegensatze zu ersterem nur Pseudoephedrin erhielt. Dieses Alkaloid mit

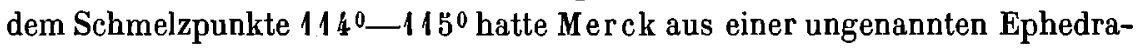
art dargestellt. Die Untersuchung ergab, daß es isomer mit dem Ephedrin

1) Chem.-Zeitg. $1890,1,441$.

2) Mercks Berichte 1893.

3) Archiy der Pharm. 1902, S. 401. 
Die Krystallformen usw. der Ephedrin-, Damascenin- und Aconitingruppe.

ist; beide sind secundäre Basen. Die chemische Zusammensetzung des Pseudoephedrins ist nach Ladenburg:

$$
\begin{array}{r}
\mathrm{C}_{10} \mathrm{H}_{15} \mathrm{NO}=\mathrm{C}_{6} \mathrm{H}_{5}-\mathrm{CH}-\mathrm{OH}-\mathrm{CH}-\mathrm{CH}_{3} . \\
\mathrm{N} \mathrm{NH}_{3}
\end{array}
$$

Von verschiedenen Seiten sind mit ungleichem Erfolge Versuche gemacht worden, das Ephedrin in Pseudoephedrin umzulagern; besonders beschäftigt haben sich damit Schmidt, Nagai, Flaecher und Emde. Anfangs gelang es nur, einen kleinen Teil des verwendeten Ephedrins in Pseudoephedrin überzuführen, da ein Teil des Ausgangsmalerials einer Zerselzung unterworfen war. Später fanden E. Schmidt und H. Emde ${ }^{1}$ ), daß, wenn man 25 procentige Salzsäure auf Ephedrin im Wasserbade einwirken läßt, ein beträchtlicher Teil in Pseudoephedrin umgelágert wird, während der Rest unverändert bleibt. Ausgegangen wurde dabei vom Ephedrinchlorhydrat mit dem Schmelzpunkte $216^{\circ}$, aus dem schließlich aus wässeriger Lösung Pseudoephedrin gewonnen wurde.

Nachdem es auf diese Weise gelungen war, das Pseudoephedrin durch Umlagerung aus Ephedrin zu erhalten, kam es darauf an festzustellen, ob das erhaltene Product identisch sei mit dem direct aus der Ephedra vulg. dargestellten Pseudoephedrin. Zu diesem $Z$ wecke wurden beide einer optischen, chemischen und krystallographischen Untersuchung unterworfen mit dem am angegebenen Orte $^{2}$ ) bereits mitgeteilten Resultate, daß beide Substanzen sich auch krystallographisch als vollkommen identisch erweisen.

Die Krystalle sowohl des sumgelagerten Pseudoephedrins\&, als auch die der »natürlichen Base sind aus einer Lösung in Äther erhalten. Beide haben ihren Schmelzpunkt bei $117,5^{\circ}$.

Pseudoephedrin, natürliche Base.

Fig. 1.

Krystallsystem: Rhombisch.

Axenverhältnis :

$a: b: c=0,84492: 1: 1,8598$.

Beobachtete Formen: $c\{001\}$, $n\{101\}, d\{011\}, e\{012\}$.

$$
\text { Gemessen: }
$$

Berechnet: Anzahl der
Messungen :

$\begin{array}{llllllr}c: n=(001):(101)=65^{0} 34^{\prime} & - & 31 & 65^{0} & 0^{\prime}-65^{0} 52^{\prime} \\ e: d=(001):(011) & 6144 & - & 35 & 61 & 4-62 & 7 \\ n: n=(101):(10 \overline{1}) & 4850 \frac{1}{2} & 48^{0} 54^{\prime} & 21 & 48 & 3-49 & 16 \\ c: e=(001):(012) & 4257 & 4255 & 3 & 4254-43 & 0\end{array}$

1) Archiv der Pharm. 1906, S. 239.

2) Emde, Beiträge zur Kenntnis des Ephedrins und Pseudoephedrins. Dissert. Marburg 1906; desgl. Archiv der Pharmacie 1906, S. 241. 
I. Schwantke.

\begin{tabular}{|c|c|c|c|c|}
\hline & Gemessen: & Berechnet: & $\begin{array}{l}\text { Anzahl der } \\
\text { Messungen: }\end{array}$ & Grenzen \\
\hline$e: d=(012):(011)$ & $=18^{0} 43^{\prime}$ & $18^{0} 46^{\prime}$ & 3 & $18^{0} 31^{\prime}-18^{0} 54^{\prime}$ \\
\hline$e: d=(012):(01 T)$ & 757 & 7518 & 8 & $74 \quad 17-77 \quad 10$ \\
\hline$d: d=(011):(01 \overline{1})$ & $5625 \frac{1}{2}$ & $56 \quad 32$ & 15 & $56 \quad 1-56 \quad 45$ \\
\hline$e: e=(012):(01 \overline{2})$ & 一 & $94 \quad 4$ & - & - \\
\hline$n: e=(101):(012)$ & $72 \quad 24$ & 7929 & 2 & $7223-7225$ \\
\hline$n: d=(101):(011)$ & $78 \quad 40$ & $78 \quad 42$ & 38 & $78 \quad 12-79 \quad 25$ \\
\hline
\end{tabular}

Die $\mathbf{2}-\mathbf{5} \mathbf{~ m m}$ großen Krystalle waren von klarer und durchsichtiger Beschaffenheit. Von den genannten Formen waren gewöhnlich nur die ersten drei, d. h. die Basis und die beiden primären Domen vorhanden, und zwar größtenteils in guter und deutlicher Ausbildung, so daß sich die Krystalle leicht orientieren ließen. Sie waren gewöhnlich etwas gestreckt nach der Brachyaxe, nur in einem Falle war die Unterscheidung der Domen vor der Winkelmessung nicht möglich, da sich die Winkel beider nur um etwa $7^{0}$ von einander unterscheiden.

Von den neun gemessenen Krystallen zeigten sieben eine übereinstimmende Ausbildung, so daß man diese als die gewöhnliche bezeichnen kann. Sie nähern sich in einigen Fällen der idealen Gestalt und zeigen allseitig gleiche Ausbildung der Flächen. Am deutlichsten treten dann die Domen $d(101)$ hervor, während die Basis sich nur als lange schmale Fläche zeigt. Oft tritt jedoch der Fall ein, daß nach der einen Richtung der Verticalaxe der Krystall verkürzt ist, so daß dann die Basis in größerer Ausbildung hervortritt. Von den beiden Abweichungen dieser gewöhnlichen Form zeigte die eine den Krystall zu einer Tafel verzerrt, die durch das Vorherrschen der zwei parallelen Gegenflächen des Domas $d$ hervorgerufen wurde. In dem anderen Falle fehlte die gewöhnliche Streckung des Individuums nach der $a$-Axe, so daß die Domen $n$ und $d$ in gleich großer Ausbildung auftraten. Die Basis war hier nur einmal als schmale Fläche vertreten. Das Doma $e(012)$ war nur einige Male als schmale Fläche mit schlechter Ausbildung zu beobachten.

Die Krystalle besitzen eine ausgezeichnete Spaltbarkeit nach der Basis.

Die Messungen lieferten ziemlich brauchbare Resultate, da die Flächenbeschaffenheit und die Güte der Signale für die hauptsächlichsten drei Flächen genügend genannt werden konnte. Die Untersuchungen wurden wesentlich erschwert durch den Umstand, daß die Krystalle gegen mechanischen Druck äußerst empfindlich sind und sich beim Berühren mit der Hand an den Ecken und Kanten leicht verbiegen, wodurch die Güte der Signale sehr beeinträchtigt wird. Spaltblältchen nach der Basis von etwa $1 \mathrm{~mm}$ Dicke lassen sich sowohl in der Richtung der Brachy- als in der Richtung der Makroaxe falten, ohne zu zerbrechen. Diese hervorragende Biegsamkeit ist eine ebenso charakteristische wie interessante Eigenschaft 
dieser Krystalle. Das vorhandene Material war leider qualitativ und quantitativ nicht ausreichend, um sie eingehender physikalisch zu studieren. Aber es dürfte sich wohl verlohnen, einmal das Pseudoephedrin zu diesem Zwecke in größerer Menge darzustelllen. Die vorliegenden krystallographischen Bestimmungen werden dann diesen Untersuchungen zur Grundlage dienen können.

\section{Umgelagertes Pseudoephedrin.}

Krystallsystem: Rhombisch.

Axenverhältnis: $\quad a: b: c=0,84142: 1: 1,8563$.

Beobachtete Formen: $c\{001\}, d\{011\}, n\{101\}, e\{012\}$. (siehe Fig. 1 des isomorphen Pseudoephedrins, natürliche Base).

Gemessen: Berechnet: Anzahl der Messungen: Grenzen:

$\begin{array}{lllllll}c: n=(001):(101)=65^{0} 37^{\prime} & - & 30 & 65^{0} & 1^{\prime}-66^{0} 18^{\prime} \\ c: d=(001):(011) & 6141 \frac{1}{2} & - & 29 & 61 & 5-62 & 15 \\ n: n=(101):(10 \overline{1}) & 4849 & 48^{0} 46^{\prime} & 18 & 48 & 0-49 & 47 \\ c: e=(001):(012) & 4254 \frac{1}{2} & 4252 & 26 & 42 & 46-43 & 15 \\ e: d=(012):(011) & 1849 & 1849 & 19 & 18 & 14-19 & 13 \\ e: d=(012):(01 \overline{1}) & 7519 \frac{1}{2} & 7527 & 16 & 75 & 7-76 & 4 \\ d: d=(011):(01 \overline{1}) & 5637 & 5638 & 7 & 56 & 0-56 & 40 \\ e: e=(012):(01 \overline{2}) & 9416 & 9416 & 9 & 94 & 5-94 & 44 \\ n: e=(101):(012) & 7224 & 7223 & 16 & 7211-72 & 31 \\ n: d=(101):(011) & 7840 \frac{1}{2} & 7843 & 20 & 78 & 22-79 & 38\end{array}$

Die Krystalle waren im allgemeinen besser ausgebildet als die vorher beschriebenen, ebenfalls klar und durchsichtig und von $7-11 \mathrm{~mm}$ Länge. Der Habitus ist abweichend von denen der natürlichen Base, tafelförmig nach der Basis, die gewöhnlich sehr gut ausgebildet ist. Auch die beiden Domen sind stets vorhanden, daneben in Combination damit das Doma e\{012\}. Im Unterschiede zu der vorher beschriebenen Base tritt hier dieses Doma regelmäßiger und in besserer Ausbildung auf. In einem Falle trat sogar das primäre Doma $d$ dagegen ganz zurück und war nur als schmale Linie vorhanden. Die Krystalle. nähern sich in einigen Individuen der idealen Gestalt, gewöhnlich sind sie aber an einem Ende der Verticalaxe ziemlich schlecht ausgebildet und werden hier direct durch die Basis begrenzt. Die Streckung der Krystalle ist dabei nicht einheitlich, sie sind teils nach der Brachy-, teils nach der Makroaxe verlängert. In bezug auf die übrigen Eigenschaften; besonders was Spaltbarkeit und Biegsamkeit anbetrifft, stimmen sie vollkommen mit der natürlichen Base überein.

Gemessen worden sind ganz oder teilweise zehn Krystalle. Die Signale. erlaubten im allgemeinen eine hinreichend genaue Einstellung. 
Der Vergleich der durch die Messung erhaltenen Resultate ergibt die vollkommene Identität der beiden Substanzen. Das Axenverhältnis ist bei beiden das gleiche:

Natürliche Base: $\quad a: b: c=0,84492: 1: 1,8598$.

Umgel. Pseudoeph.: $a: b: c=0,84142: 1: 1,8563$.

Die Abweichungen liegen vollkommen innerhalb der Fehlergrenzen und die absolute Übereinstimmung der charakteristischen physikalischen Eigenschaften läßt an der Identität keinen $Z$ weifel. Die geringen Abweichungen in der Ausbildung der Krystalle sind wohl durch gewisse Unterschiede der Krystallisationsbedingungen der im übrigen in gleicher Weise aus Lösung in Äther gewonnenen Krystalle zu erklären.

Ephedrin und Pseudoephedrin, und zwar von diesem sowohl das aus der Pflanze direct dargestellte, als auch das durch Umlagerung aus Ephedrin erhaltene zeigen in ihrem Verhalten gegen Jodmethyl die gleiche Eigenschaft, daß sich in die Moleküle eine oder auch zwei Methylgruppen einführen lassen. Von den so erhaltenen Verbindungen lagen die quaternären Jodide vor, also Methylephedrinmethyljodid und die entsprechende Verbindung des Pseudoephedrins. Diese beiden Substanzen haben ihrerseits die Eigentümlichkeit, daß sie sich im Gegensatze zu den freien Basen in ihren Schmelzpunkten sehr nahe stehen, woraus man schließen zu künnen glaubte, daß.die Verschiedenheit der beiden isomeren Alkaloide durch den Eintritt der beiden Methylreste aufgehoben sein könnte. Es wurden daher die Krystalle der genannten zwei Verbindungen gemessen und außerdem auch die Jodide des nicht methylierten Ephedrins und Pseudoephedrins untersucht, um beide auf ein ähnliches Verhalten zu prüfen und zugleich auch die morphotropische Wirkung der Methylierung zu studieren.

Von großer Wichtigkeit wäre es auch gewesen, das Ephedrin und Pseudoephedrin selbst mit einander zu vergleichen. Leider gelang es wegen des niedrigen Schmelzpunktes des Ephedrins nicht, dieses in meßbaren Krystallen darzustellen.

Fig. 2.

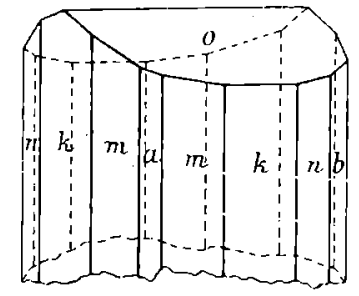

Da für die krystallographische Gegenüberstellung der einzelnen Glieder die Reihenfolge der Beschreibung unwesentlich ist, soll mit den nicht methylierten Jodiden begonnen werden.

\section{Ephedrinhydrojodid $C_{10} H_{15} N O . H J$.}

Die Darstellung erfolgte durch Neutralisation einer gesättigten alkoholischen Lösung des freien Ephedrins mit frisch destillierter, farbloser Jodwasserstoffsäure. Die Krystalle wurden durch freiwilliges Verdunstenlassen dieser Lüsung erhalten. Ihr Schmelzpunkt liegt bei $155^{0}-156^{\circ}$. 
Krystallsystem: Rhombisch, hemiëdrisch (bisphenoïdisch).

Axenverhältnis: $\quad a: b: c=0,73703: 1: 0,28643$. $x\{0 \bar{T} 1\}$.

Beobachtete Formen: $a\{100\}, b\{010\}, k\{110\}, m\{210\}, n\{120\}, o\{111\}$,

Gemessen: Berechnet: Anzahl der

Messungen: Grenzen:

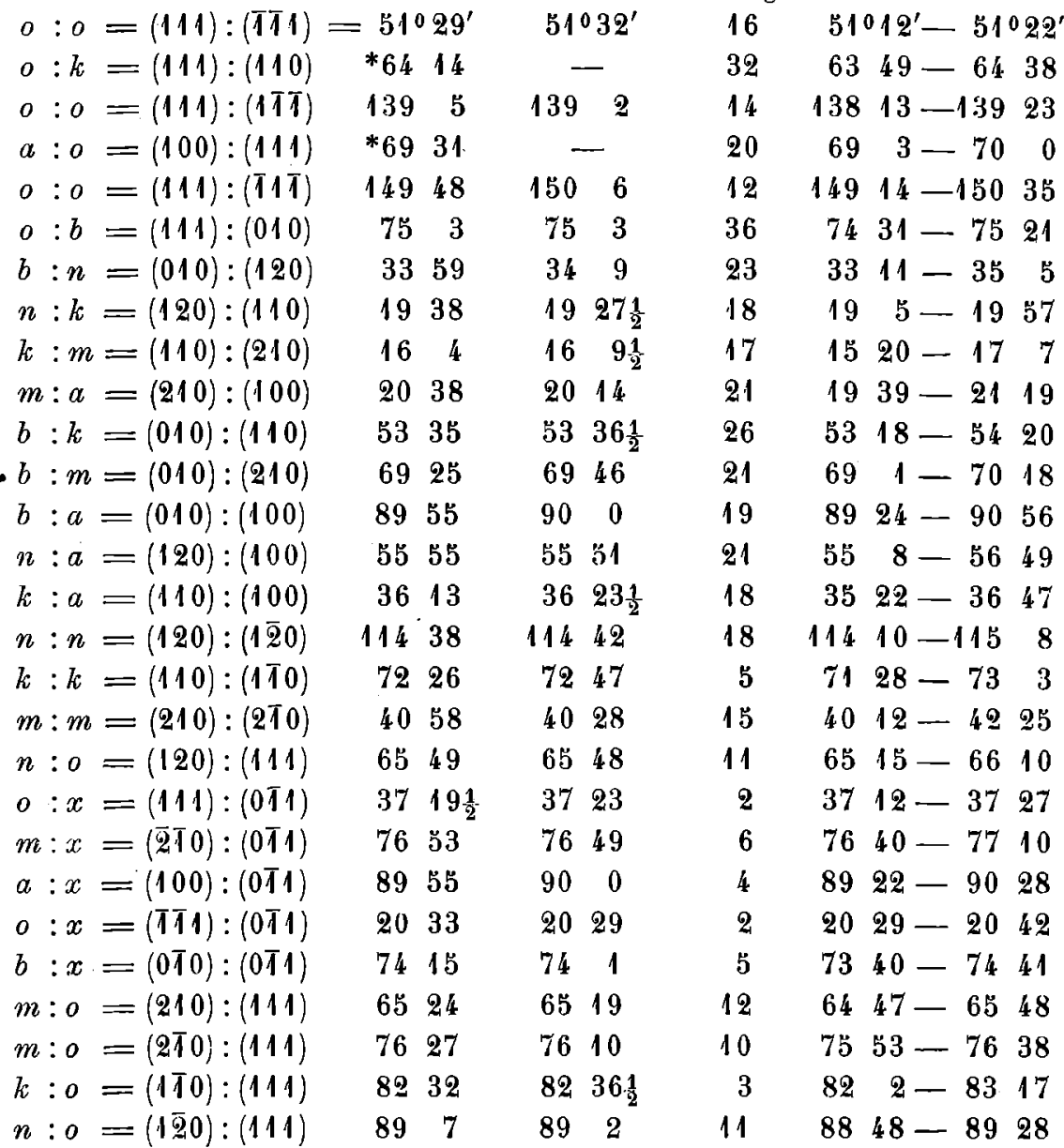

Gemessen wurden neun Krystalle. Sie waren $2-3 \mathrm{~mm}$ groß, klar und durchsichtig und sämtlich von übereinstimmendem Habitus. Die Flächen der Prismenzone fanden sich meist in unter einander gleicher Ausbildung in Form langer mehr oder weniger schmaler Rechtecke, so daß die Krystalle, äußerlich betrachtet, rund erscheinen. Zuweilen waren sie auf der Seite, wo sie aufgesessen haben, abgeflacht, so daß die Prismen nur mit einer Fläche ausgebildet sind und die Krystalle halbrund erscheinen. Die beiden Enden sind stets deullich durch die Bisphenoïdfächen abgeschlossen, 
die sich meist in guter Ausbildung zeigten und die besten Reflexe gaben.

Die Signale der Prismenflächen waren, da die Krystalle meist corrodiert sind, weniger gut, immerhin zeigt sich zwischen den Messungen und Berechnungen hinreichende Übereinstimmung. Außer den Flächen der Prismenzone und den Bisphenoïdflächen wurde in einem Falle das Brachydoma $x\{0 T 1\}$ in Form eines kleinen Dreiecks constatiert; andere Flächen traten nicht auf.

Eine Spaltbarkeit war nicht zu ermitteln. Die Auslöschung ist auf allen Prismenflächen gleich.

Pseudoephedrinhydrojodid $\mathrm{C}_{10} \mathrm{H}_{25} \mathrm{NO} . \mathrm{HJ}$.

Fig. 3.

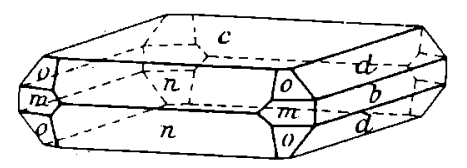

Die Darstellung erfolgte analog der des Ephedrinjodids unter Anwendung von Pseudoephedrin. Die Substanz schmilzt bei $172^{\circ}$.

Krystallform: Rhombisch holoëdrisch (bipyramidal).

Axenverhältnis: $\quad a: b: e=0,60282: 1: 1,3722$.

Beobachtete Formen: $c\{001\}, d\{011\}, n\{101\}, o\{111\}, b\{010\}, m\{110\}$.

Gemessen: Berechnet: Anzahl der Gessungen: Grenzen:

\begin{tabular}{|c|c|c|c|c|c|c|c|}
\hline$: d=(001):(011)$ & $=53^{\circ}$ & $055^{\prime}$ & $53055^{\prime}$ & 12 & & $021-54$ & $021^{\prime}$ \\
\hline$d: d=(011):(01 \pi)$ & & 10 & - & 10 & 71 & $24-72$ & 37 \\
\hline$: b=(011):(010)$ & 36 & 8 & 365 & 16 & 35 & $41-36$ & 30 \\
\hline$: n=(001):(101)$ & 66 & 17 & - & 19 & 65 & $53-66$ & 34 \\
\hline$: n=(101):(10 \pi)$ & 47 & 21 & 4726 & 11 & 47 & $7-47$ & 42 \\
\hline$: b=(001):(010)$ & 89 & 52 & $90 \quad 0$ & 10 & 89 & $43-90$ & 15 \\
\hline$: o=(001):(111)$ & 69 & 22 & 6923 & 24 & 69 & $1-69$ & 57 \\
\hline$: m=(001):(110)$ & 90 & 6 & $90 \quad 0$ & 14 & 88 & $55-90$ & 24 \\
\hline$: m=(111):(110)$ & 20 & 40 & 2037 & 12 & 19 & $59-21$ & 48 \\
\hline$o: o=(111):(11 \pi)$ & 41 & 17 & $41 \quad 14$ & 17 & 40 & $51-4.1$ & 40 \\
\hline$o: o=(111):(1 T 1)$ & 57 & 32 & 5748 & 16 & 56 & $56-57$ & 40 \\
\hline$o: o=(111):(11 T)$ & 73 & 15 & 7324 & 8 & 72 & $47-73$ & 39 \\
\hline$o: b=(111):(010)$ & 61 & 21 & 616 & 32 & 60 & $50-61$ & 54 \\
\hline$o: n=(111):(101)$ & 28 & $45 \frac{1}{2}$ & 2854 & 20 & 28 & $14-29$ & 8 \\
\hline$n: b=(101):(010)$ & 89 & 48 & $90 \quad 0$ & 22 & 89 & $10-90$ & 25 \\
\hline$o: d=(111):(011)$ & 53 & 37 & $53 \quad 17$ & 20 & 53 & $0-53$ & 53 \\
\hline$m: d=(110):(011)$ & 65 & 27 & 6521 & 10 & 64 & $54-65$ & 38 \\
\hline$m: n=(110):(101)$ & 38 & 8 & 3820 & 12 & $3 \pi$ & $50-38$ & 21 \\
\hline$n: d=(101):(01 \bar{T})$ & 76 & 26 & $76 \quad 18$ & 16 & 75 & $44-76$ & 47 \\
\hline$m: m=(110):(1 \bar{\top} 0)$ & 61 & 53 & 6210 & 4 & 61 & $40-62$ & 13 \\
\hline$b: m=(010):(110)$ & 59 & $0 \frac{1}{2}$ & 5855 & 8 & 5.8 & $37-60$ & 17 \\
\hline
\end{tabular}


Die Krystalle waren in verschiedenen Abstufungen bis $17 \mathrm{~mm}$ groß, etwas weniger breit und meist von tafeligem Habitus. Zuweilen waren sie durch freies Jod schwach gelb gefärbt, im allgemeinen farblos und durchsichtig. Von einer übereinstimmenden Ausbildung kann nicht gesprochen werden, wenn auch die Tafelform mit dem Vorherrschen der Basis das Gewöhnliche zu sein scheint. Von den untersuchten Krystallen zeigten zwei die Neigung zu tafeligem Habitus nach der Querfläche.

Am flächenreichsten waren die, welche die Basis zur Ta felfläche haben: Sie zeigten alle oben genannten Flächen in deutlicher Ausbildung und näherten sich zuweilen der idealen Gestalt. Gewöhnlich waren allerdïngs die Kanten und Ecken gerundet, doch hatte das auf die Güte der Signale wenig Einfluß. Die Messungen sind als ziemlich genau zu bezeichnen. Wenn auch die Signale im allgemeinen ziemlich schwach waren, waren sie doch einheitlich und machten eine genügend sichere Einstellung müglich. Die Abweichung von der gewöhnlichen Krystallform mit dem Vorherrschen der Basis, die, wie gesagt, in den beiden erwähnten Fällen mit der Tafelform nach der Querfläche auftrat, hatte hier gleichzeitig eine Verminderung des Flächenreichtums in der Weise zur Folge, daß neben der Querfläche und der Basis nur das Doma $d\{011\}$ und die Pyramide $o\{111\}$ auftraten.

Unter dem Polarisationsmikroskope zeigten die Krystalle parallele Auslöschung auf der Basis und der Querfläche nach der Combinationskantë beider Flächen.

Fig. 4.

Methylephedrinmethyljodid $C_{9} H_{10}(O H) N\left(C H_{3}\right)_{3} J$.

Die Substanz wird dargestellt durch Behandeln einer methylalkoholischen Lösung mit Jodmethyl. Nach dem Verdunsten des Lösungsmittels erhält man durch Umkrystallisieren aus Methylalkohol das Alkaloid in Krystallen mit dem Schmelzpunkte bei $199^{\circ}$.

Krystallform: Rhombisch, hemiëdrisch (bisphenoïdisch).

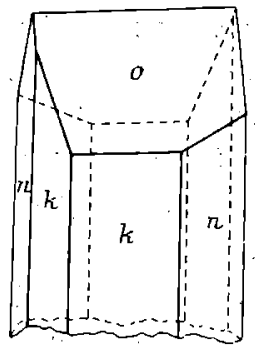

Axenverhältnis: $\quad a: b: c=0,97926: 1: 0,76088$.

Beobachtete Formen: $k\{110\}, n\{120\}, o\{111\}, e\{101\}$.

Gemessen: Berechnet: Anzahl der

Grenzen:

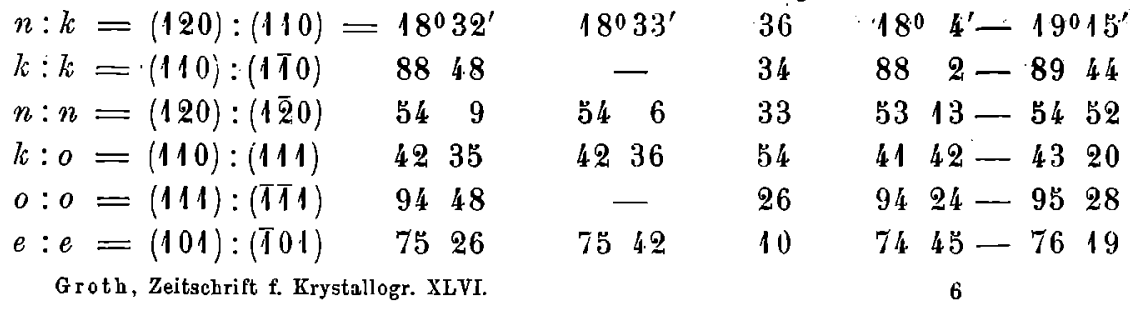




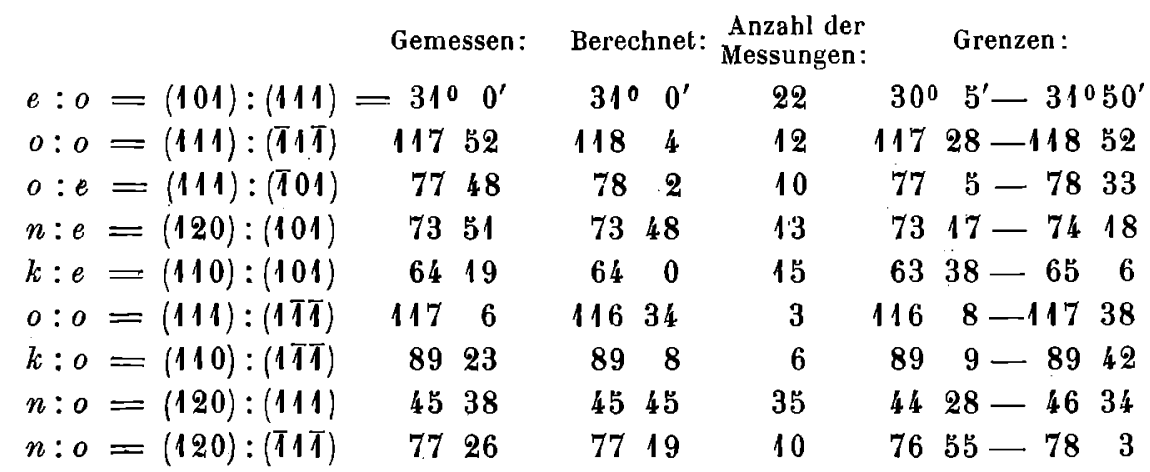

Die Krystalle waren durchweg nicht größer als 1-2 mm, klar und durchsichtig und von ausgesprochen sphenoïdischem Habitus. Einige sehr gut ausgebildete Krystalle erinnerten an die des Bittersalzes. Die Aufstellung ist mit Rücksicht darauf, daß auch das Ephedrinjodid denselben sphenoïdischen Habitus zeigt, correspondierend mit diesem gewählt worden.

Bei den gut ausgebildeten Krystallen herrschten von den Endflächen die Bisphenö̈dflächen vor, bei anderen dagegen, wo sie in Combination mit dem Makrodoma $e\{101\}$ traten, wurden sie von dieser Fläche zuweilen zurückgedrängt, so daß der sphenoïdische Habitus nicht immer ohne weiteres deutlich erkennbar war. Die Domenflächen waren niemals vollzählig vorhanden, gewöhnlich fehlte eine oder mehrere, zuweilen alle; die vorhandenen waren teils sehr klein, teils traten sie, wie oben erwähnt, deutlicher neben dem Bisphenoïd hervor. In der Prismenzone fanden sich regelmäßig das primäre Prisma $k$ und das Verticalprisma $n\{120\}$. In einigen Fällen machte sich Tafelform nach $k$ bemerkbar, doch sind das Ausnahmen.

Fast alle Krystalle waren nach der Verticalaxe gestreckt, das Gegenteil war allerdings ebenfalls zu beobachten. Die Flächen waren fast durchweg so ausgebildet, daß eine Orientierung der Krystalle schon bei der Betrachtung mit bloßem Auge möglich war. Sie waren glatt und eben und gaben auf dem Goniometer genügende und gute Reflexe, so daß aus den Messungen der zehn gemessenen Krystalle die Constanten sich mit vollkommener Sicherheit berechnen ließen. Eine Übereinstimmung mit dem Ephedrinjodid konnte nur mit Bezug auf das Krystallsystem, nicht aber in den Winkeln festgestellt werden.

Die Auslöschung ist auf den Prismenflächen parallel der Verticalaxe. 


\section{Methylpseudoephedrinmethyljodid $\mathrm{C}_{9} \mathrm{H}_{10}(\mathrm{OH}) \mathrm{N}\left(\mathrm{CH}_{3}\right)_{3} J$.}

Die Darstellung entspricht ganz der des Methylephedrinmethyljodids bei Anwendung von Pseudoephedrin. Der Schmelzpunkt liegt bei $205^{\circ}$.

Krystallform : Rhombisch holoëdrisch (bipyramidal).

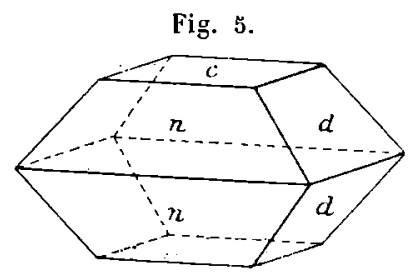

Axenverhältnis :

$$
a: b: c=0,64227: 1: 1,2088 .
$$

Beobachtete Formen: $c\{001\}, d\{011\}, n\{101\}$.

$$
\text { Gemessen: Berechnet: Anzahl der Messungen: Grenzen: }
$$

$\begin{array}{lcccccc}d: d=(011):(01 T)=79^{\circ} 32^{\prime} & - & 21 & 78 & 33^{\prime}-80^{0} & 2^{\prime} \\ n: n=(101):(10 T) & 5558 & - & 13 & 5514-56 & 33 \\ d: n=(011):(101) & 7245 & 72036^{\prime} & 38 & 72 & 3-7358 \\ c: d=(001):(011) & 50 & 9 & 5024 & 3 & 50 & 8-5010 \\ c: n=(001):(101) & 62 & 5 & 621 & 2 & 6140-62 & 29\end{array}$

Die Krystalle waren 1-2 mm groß, anfangs klar und durchsichtig, wurden aber bei längerer Aufbewahrung vollkommen weiß und undurchsichtig und zerfielen schließlich zu Pulver. Gewöhnlich stellten sie die Combination der beiden primären Domen dar und zeigten dann zum Teil regelmäßige Form. Zwei von den meßbaren Krystallen zeigten das Bestreben, eine Tafelform zu bilden, und zwar nach der Basis. Da sie jedoch auf dieser. Fläche aufgesessen zu haben schienen, waren davon keine sicheren Reflexe zu erhalten. Auch die parallele Gegenfläche war nur sehr unvollkommen vorhanden. Die Signale der Domenflächen müssen ebenfalls als ungenügend bezeichnet werden, die Resultate können mithin keinen Anspruch auf große Genauigkeit machen.

Von einer optischen Untersuchung mußte Abstand genommen werden, da das vorhandene Material in den oben beschriebenen Zustand übergegangen war.

\section{Die Vergleichung der krystallographischen Verhältnisse}

der methylierten und nicht methylierten Körper ergibt noch deutlicher und zuverlässiger als die geringen Abweichungen im Schmelzpunkte, daß die Verschiedenheit der beiden isomeren Alkaloide, die sich auch in der Verschiedenheit der Krystallform der beiden Jodide zu erkennen gibt, durch die Methylierung keineswegs aufgehoben wird.

Eine ersichtliche morphotropische Wirkung der Methylierung läßt sich in den Axenverhältnissen und Winkeln höchstens in einer gewissen Ähnlichkeit der Axenverhältnisse in der Pseudoephedringruppe feststellen. 
Pseudoephedrin-Jodid:

$$
a: b: e=0,60282: 1: 1,3722,
$$

Methylpseudoephedrin-Methyljodid :

$$
a: b: c=0,64227: 1: 1,2088 \text {. }
$$

Auch für die Verbindungen des Ephedrins könnte man eine solche erwarten, wie sich aus der Gegenüberstellung der Formeln (die Formel für Ephedrin nach Emde, Dissertation S. 17, als richtig angenommen) ergiebt:

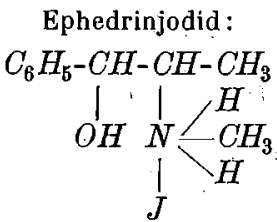

$$
\begin{gathered}
\text { Methylephedrinmethyljodid: } \\
\mathrm{C}_{6} \mathrm{H}-\mathrm{CH}-\mathrm{CH}-\mathrm{CH}_{3} \\
\mathrm{OH} \underset{\mathrm{N}}{\mathrm{N}}-\mathrm{CH}_{3}
\end{gathered}
$$

Die Vergleichung der Axenverhältnisse und Winkel ermüglicht aber nicht - auch durch keinerlei Umrechnung oder Vertauschung - eine solche Beziehung zu constatieren. Immerhin zeigt sich aber eine andere auffallende Analogie der Ephedrinverbindungen im Vergleiche zu denen des Pseudoephedrins. Sowohl das Ephedrinhydrojodid als auch das Methylephedrinmethyljodid sind bisphenoïdisch-hemiëdrisch, während die entsprechenden Pseudoephedrinverbindungen wie auch die freie Base holoëdrisch krystallisieren. Damit hat die krystallographische Untersuchung ein neues Charakteristikum geliefert, das vielleicht auch für die Auffassung der Structur von Bedeutung werden kann, da sich nach Analogie anderer Fälle vermuten läßt, daß dieser Unterschied, wenn er sich auch in weiteren Fällen als Gruppencharakteristikum erweist, in der Structur des Moleküls der beiden Isomeren seinen Grund haben wird. Es wäre gerade deshalb sehr interessant und wünschenswert, zu untersuchen, ob dieser Unterschied zwischen hemiëdrischem und holoëdrischem Charakter auch noch an anderen Verbindungen des Ephedrins und Pseudoephedrins sich bestätigen ließe.

\section{Das Damascenin, das umgelagerte Damascenin und ihre Chlor-, Brom- und Jodwasserstoffsalze.}

Das Damascenin ist ein Alkaloid, das aus dem Samen der Nigella damascena hergestellt wird. Mit der Darstellung, den Untersuchungen der Eigenschaften und der Zusammensetzung des Damascenins und seiner Verbindungen mit Säuren haben sich zuerst A. Schneider-Erlangen ${ }^{1}$, später Pommerehne-Marburg ${ }^{2}$ ) und 0 . Keller-Marburg ${ }^{3}$ ) beschäftigt. Von

1) A. Schneider, Dissertation Erlangen 1890:

2) Archiv d. Pharm. 1899, 475; 1900, 191; 1901, 217.

3) 0. Keller, Dissertation Marburg 1903. 
Herrn Dr. Keller wurde das für die nachstehenden Untersuchungen verwendete Material im pharmaceutischen Institute der Universität Marburg dargestellt.

Als empirische Formel des Damascenins wurde von. Pommerehne $C_{9} H_{11} N_{3}$ gefunden. Keller gelangte durch seine Analysen zu demselben Ergebnisse und stellte auch die weiter unten wiedergegebenen Structurformeln auf.

Das Damascenin ist eine schwache Base, die aus dem eingangs erwähnten Material schwer in Krystallen, meist nur in Form einer syrupdicken Flüssigkeit zu erhalten ist. Der Schmelzpunkt des Alkaloids liegt bei $26^{\circ}$, eine krystallographische Untersuchung der Substanz konnte aus diesen Gründen nicht vorgenommen werden.

\section{Damasceninhydrochlorid $\mathrm{C}_{9} \mathrm{H}_{11} \mathrm{NO}_{3} \cdot \mathrm{HCl}+\mathrm{H}_{2} \mathrm{O}$.}

Die Darstellung dieses Salzes erfolgte in der Weise, daß eine Auflösung der reinen Base in Äther mit fünfprocentiger Salzsäure geschüttelt wurde. Die saure Lösung wurde bei einer Temperatur von $40^{\circ}-50^{\circ}$ eingedampft und der Rückstand aus schwach angesäuertem Wasser umkrystallisiert. Die so erhaltene Verbindung hat ihren Schmelzpunkt bei $193^{\circ}-197^{\circ}$ und krystallisiert mit einem Krystallwassergehalte von 1 Mol. im Gegensalze zum Bromwasserstoff- und Jodwasserstoffsalze.

Krystallsystem: Triklin (pinakoidal).

Axenverhältnis: $\quad a: b: c=0,66527: 1: 0,45318$.

$$
\begin{array}{ll}
\alpha=89^{\circ} 51^{\prime} 18^{\prime \prime} & A=89^{\circ} 40^{\prime} 29^{\prime \prime} \\
\beta=1033052 & B=103322 \\
\gamma=891154 & C=89840 .
\end{array}
$$

Beobachtete Formen: $a\{100\}, b\{010\}, p\{011\}, s\left\{0 T_{1}\right\}, m\{1 \overline{2} 0\}, o\{111\}$. (Vergl. Fig. 8 des entsprechenden $\mathrm{HCl}$-Salzes des umgelagerten Damascenins.)

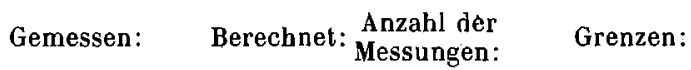

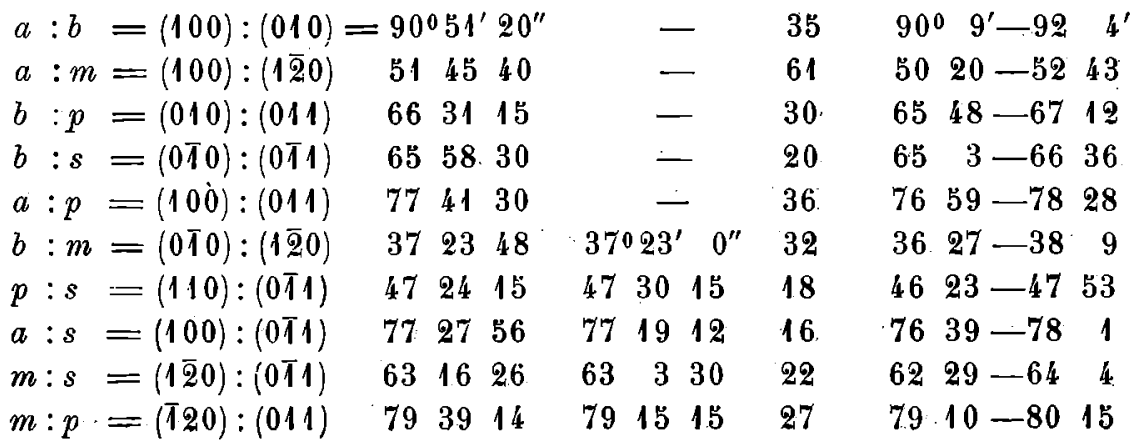


K. Schwantke.

\begin{tabular}{|c|c|c|c|c|c|c|c|}
\hline \multirow[b]{2}{*}{$m: o$} & \multirow[b]{2}{*}{$=(\bar{T} 20):(\bar{T} 11)$} & \multicolumn{3}{|c|}{ Gemessen: } & Berechnet: & $\begin{array}{l}\text { Anzahl der } \\
\text { Messungen: }\end{array}$ & \multirow{2}{*}{$\begin{array}{c}\text { Grenzen: } \\
56^{0} 14^{\prime}-58^{0} 14^{\prime}\end{array}$} \\
\hline & & 570 & $012^{\prime}$ & $0^{\prime \prime}$ & $57021^{\prime} 30^{\prime \prime}$ & 13 & \\
\hline$a: o$ & $=(T 00):(T \mid 1)$ & 67 & 4 & 0 & $66 \quad 54 \quad 40$ & 10 & $\begin{array}{llll}66 & 31-68 & 12\end{array}$ \\
\hline$b: o$ & $=(010):(\bar{T} 11)$ & 67 & 25 & 0 & $67 \quad 27$ & 6 & $6624-6750$ \\
\hline$p: o$ & $=(011):(T 11)$ & 35 & 26 & 36 & $\begin{array}{lll}35 & 23 & 50\end{array}$ & 4 & $5-3557$ \\
\hline$s: o$ & $=(0 T 1):(T / 1)$ & 59 & 40 & 0 & 5935 & 3 & $59 \quad 17-5953$ \\
\hline
\end{tabular}

Die Krystalle waren nadelförmig von etwa $1 \mathrm{~mm}$ Durchmesser mit einer Längsausdehnung bis zu $15 \mathrm{~mm}$. Natürliche Krystallflächen waren nur spärlich vorhanden. In der Längsrichtung waren in der Regel drei Flächen ausgebildet, außerdem wurde in einigen Fällen eine einzige natürliche Endbegrenzungsfläche festgestellt. In der Regel waren beide Enden der Nadeln durch Spaltungsflächen begrenzt, die beim Herausnehmen der einzelnen Krystalle aus dem durch einander gewachsenen Krystallaggregate entstanden. Es sind von diesen Spaltflächen zwei zu unterscheiden, die bald mit einander einen einspringenden, bald einen ausspringenden Winkel bilden.

Die Aufstellung der Krystalle erfolgte so, daß ihre Verticalaxe parallel der Längsausdehnung geht. Dann enthält diese Zone die Querfläche $a\{100\}$, die Längsfläche $b\{110\}$ und das Verticalprisma $m\{1 \overline{2} 0\}$. Querfläche und Längsfläche stehen fast auf einander senkrecht, der gegenseitige Neigungswinkel beträgt $90^{\circ} 51^{\prime} \mathbf{2} 0^{\prime \prime}$. Die Querfläche tritt immer in der gleichen Breite wie das Prisma $m$ auf, wohingegen die Längsfläche stets nur als ganz schmale Fläche sich findet, was für die leichtere Orientierung von einigem Vorteile ist. Die Hauptspaltbarkeit verläuft parallel dem Hemidoma $p\{011\}$, weniger vollkommen spaltet die Substanz nach $s\{011\}$. Die eine erwähnte natürliche Endfläche, die in einigen wenigen Fällen constatiert wurde, ergibt sich aus der Berechnung als eine Viertelpyramide mit den Indices $o\{\overline{1} \mid 1\}$.

Gemessen worden sind 14 Krystalle oder Bruchstücke davon, die zum Teil allerdings nur in der Hauptzone brauchbare Werte lieferten. Die Signale waren im allgemeinen schlecht, wie die verhältnismäßig weiten Grenzwerte zeigen. Die besten Reflexe waren von der oberen Spaltfläche $p\{011\}$ zu erhalten.

Unter dem Mikroskope zeigte sich, daß die Auslöschung auf der Querfläche nur ganz wenig schief war und etwa $1^{0}$ betrug; auf dem Prisma $m\left\{1 \overline{\mathbf{Z}}_{0} 0\right\}$ ist sie im Mittel zu $\mathbf{8}^{0} \mathbf{3 4}^{\prime}$ gemessen worden. Das Verhalten der Krystalle in bezug auf die Längsfläche konnte infolge deren geringer Ausbildung nicht festgestellt werden.

In zwei Fällen wurde Zwillingsbildung beobachtet nach dem Gesetze: Zwillingsaxe ist die Verticalaxe, Verwachsungsfläche die Querfläche. Man erkennt die Zwillingsnatur an den einspringenden. Winkeln, die die Spalt- 
flächen des einen Individuums mit denen des anderen machen. Dabei liegt das Hemidoma $p\{011\}$ des einen mit dem Hemidoma $s\{0 \overline{1} 1\}$ des anderen fast in einer Zone mit den Längsflächen.

\section{Damasceninbydrobromid $\mathrm{C}_{9} \mathrm{H}_{11} \mathrm{NO}_{3} \cdot \mathrm{HBr}+2 \mathrm{H}_{2} \mathrm{O}$.}

Die Darstellung des bromwasserstoffsauren Damascenins ist analog der der salzsauren Verbindung unter Anwendung einer fünfprocentigen Bromwasserstoffsäure. Die Krystalle sind aus wässeriger Lösung des Salzes erhalten, ihr Schmelzpunkt liegt in lufttrockenem $\mathrm{Zu}$ standé bei $104^{0}-106^{\circ}$. Der Krystallwassergehalt beträgt $2 \mathrm{Mol}$.

Krystallsystem: Monoklin (prismatisch). Axenverhältnis :

$$
\begin{gathered}
a: b: c=2,7575: 1: 2,4895 \\
\beta=100^{\circ} 6^{\prime} .
\end{gathered}
$$

Hig. 6.

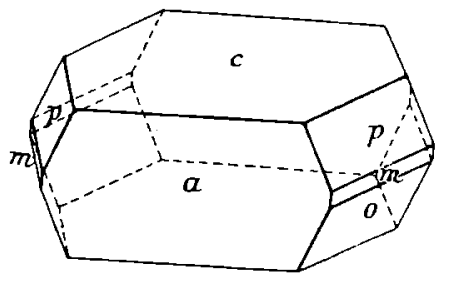

Beobachtete Formen: $a\{100\}, c\{001\}, s\{101\}, r\{10 \overline{1}\}, m\{110\} p\{111\}$, $o\{1 \mid T\}$

Gemessen: Berechnet: Anzahl der

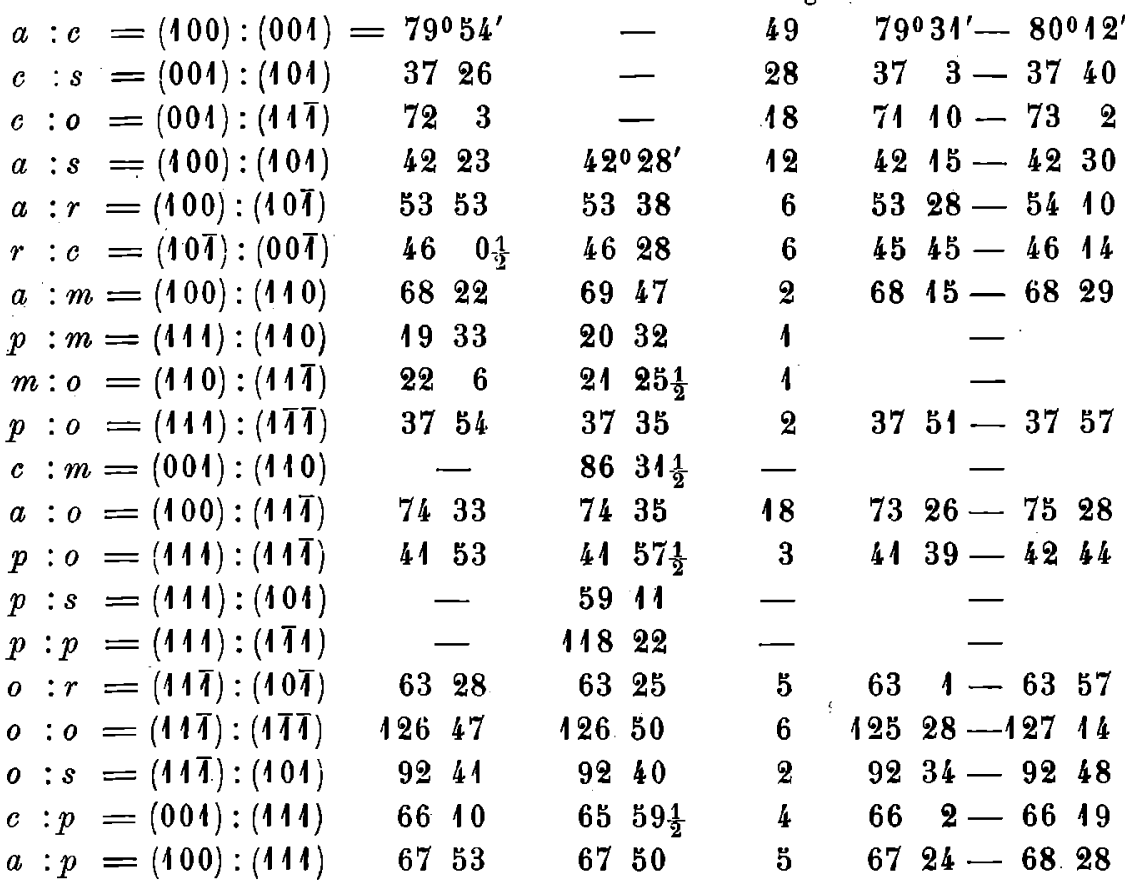

Die Ausbildung der Krystalle war unvollkommen und schlecht, so daß die Messungen auf allzugroße Genauigkeit keinen Anspruch machen können. 
li. Schwantlie.

Die Krystalle waren nach ihrer Darstellung farblos und durchsichtig, meist tafelig nach der Basis mit einer Längserstreckung nach der Orthoaxe. Ihre Größe schwankt in der Längsausdehnung zwischen 3 und $10 \mathrm{~mm}$, in der Breite zwischen 2 und $5 \mathrm{~mm}$. Vollkommen ausgebildete Krystalle lagen nicht vor; regelmäßig (mit einer Ausnahme) waren sie mit einem Ende ihrer Längserstreckung aufgewachsen, während das andere Ende freie Krystallflächen bildete. In manchen Fällen fehlten auch diese, so daB nur die Zone der Basis mit der Querfläche meßbar war. Von dem vorhandenen Materiale waren nur neun Krystalle zur Messung geeignet.

Die Basis herrscht immer vor, daneben findet sich die Querfläche in verhältnismäßig guter Ausbildung. In der Zone dieser beiden Flächen wurden ferner die beiden. Schiefendflächen $s\{101\}$ und $r\{10 \overline{1}\}$ beobachtet, die in der Regel nur als schmale Flächen ausgebildet sind. Mit der Querfläche fallen zwei in der Regel im Verhältnis zu den übrigen vorhandenen Begrenzungsflächen deutlicher ausgebildete Begrenzungsflächen in eine Zone, die Hemipyramiden $o\{1 / T\}$ und $p\{T / T\}$. Diese beiden Flächen liegen ihrerseits wieder in einer Zone mit der Basis und je zwei anderen Flächen, die an einigen Krystallen in sehr geringer Ausdehnung in Form schmaler Linien festgestellt wurden und die nach ihren berechneten. Indices die Hemipyramiden $p\{111\}$ und das Verticalprisma $m\{110\}$ sind. Andere Flächen als die genannten waren nicht zu bemerken.

Die besten Signale waren von den Flächen der Zone Basis-Querfläche zu erhalten, weshalb zwei der Berechnung zugrunde gelegte Winkel daraus entnommen sind. Die übrigen Flächen waren in der Regel sehr unvollkommen ausgebildet und zeigten keine scharfen Grenzen, sondern waren an den Kanten gerundet. Die Reflexe waren daher durchweg schlecht und unsicher. Am sichersten war der Winkel zwischen der Hemipyramide $o\{1 \mid T\}$ und der Basis zu bestimmen, und dieser Wert ist daher als dritter Winkel für die Berechnung verwendet worden.

In einem Falle wurde $Z$ willingsbildung constatiert und zwar war die Querfläche sowohl Zwillings- wie Verwachsungsfläche. Die Basisflächen der beiden Individuen machen einen einspringenden Winkel, der sich durch die Berechnung zu 200 $12^{\prime}$ ergibt. Durch die Messung wurde für den ausspringenden Winkel der Wert von $20^{\circ} 51^{\prime}$, für den einspringenden Winkel $2001^{\prime}$ ermittelt.

Die optische Untersuchung mußte sich auf die Feststellung der Auslöschung auf der Basis und der Querfläche beschränken. Sie war in beiden Fällen, den Verhältnissen des monoklinen Systems entsprechend, gerade nach der Combinationskante dieser beiden Flächen.

$\mathrm{Zu}$ bemerken ist noch, daß das Salz nach längerer Aufbewahrung deutliche Spuren der Verwitterung zeigte und undurchsichtig geworden war. Isomorph mit dem eben beschriebenen Salze ist das 
Damasceninhydrojodid $\mathrm{C}_{9} \mathrm{H}_{11} \mathrm{NO}_{3} . \mathrm{HJ}+2 \mathrm{H}_{2} \mathrm{O}$.

Von der Darstellung gilt dasselbe, was beim Chlorwasserstoffsalze gesagt ist mit dem Unterschiede, daß $H J$ statt $H C l$ angewendet wird. In Übereinstimmung mit dem Bromwasserstoffsalze krystallisiert es mit 2 Mol. Krystallwasser; sein Schmelzpunkt liegt in luftrockenem Zustande bei $1120-115^{\circ}$.

Krystallsystem: Monoklin (prismatisch).

Axenverhältnis:

$$
a: b: c=2,7519: 1: 2,4372 ; \beta=99^{\circ} 27^{\prime} .
$$

Beobachtete Formen: $a\{100\}, c\{001\}, s\{101\}, r\{10 \overline{1}\}, m\{110\}, k\{310\}$, $p\{111\}, o\{11 T\}, e\{311\}, f\{113\}$. (Vergl. Fig. 6. des isomorphen $H B r-D a-$ mascenins).

Gemessen: Berechnet: Anzahl der

\begin{tabular}{|c|c|c|c|c|c|c|c|c|}
\hline$a: c$ & $=(100):(001)$ & $=80^{\circ}$ & $033^{\prime}$ & & - & 58 & $80^{0} 21^{\prime}-81^{\circ}$ & o \\
\hline$c: p$ & $=(001):(1.1)$ & 66 & 0 & & 一 & 42 & $6539-66$ & 17 \\
\hline$a: p$ & $=(100):(111)$ & 68 & 7 & & - & 40 & $6756-68$ & 16 \\
\hline$c: s$ & $=(001):(101)$ & 37 & 22 & & $020^{\prime}$ & 12 & $37 \quad 1-37$ & 52 \\
\hline$s: a$ & $=(101):(100)$ & 43 & 21 & 43 & 13 & 12 & $4258-43$ & 46 \\
\hline$a: r$ & $=(100):(10 \overline{1})$ & 53 & $54 \frac{1}{2}$ & 53 & 49 & 22 & $5347-54$ & 14 \\
\hline$r: e$ & $=(10 \pi):(00 \pi)$ & 45 & $30 \frac{1}{2}$ & 45 & 38 & 20 & $4512-45$ & 13 \\
\hline$m: m$ & $=(110):(1 \overline{1} 0)$ & 139 & 52 & 139 & 44 & 15 & $13944-140$ & 8 \\
\hline$a: m$ & $=(100):\left(\begin{array}{lll}1 & 1 & 0\end{array}\right)$ & 69 & 56 & 69 & 52 & 48 & $6928-70$ & 12 \\
\hline$p: m$ & $=(111):(110)$ & 20 & $46 \frac{1}{2}$ & 20 & 46 & 28 & $2025-20$ & 59 \\
\hline$m: o$ & $=(110):(11 \pi)$ & 21 & 32 & 21 & $36 \frac{1}{2}$ & 3 & $21 \quad 16-22$ & 3 \\
\hline$o: c$ & $=(11 \bar{T}):(00 \bar{T})$ & 72 & 17 & 71 & $37 \frac{1}{2}$ & 3 & $72 \quad 4-72$ & 33 \\
\hline$p:: o$ & $=(1 \mid 1):(1 \overline{1} \overline{1})$ & 37 & $25 \frac{1}{2}$ & 37 & 19 & $\boldsymbol{5}$ & $3719-37$ & 48 \\
\hline$c: m$ & $=(001):(110)$ & 86 & 50 & 86 & 46 & 41 & $8622-87$ & 6 \\
\hline$a: o$ & $=(100):(11 \pi)$ & 74 & 28 & 74 & 34 & 10 & $7353-74$ & 41 \\
\hline$p: o$ & $=(111):(11 \overline{1})$ & 42 & 19 & 42 & $22 \frac{1}{2}$ & 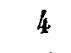 & $423-42$ & 52 \\
\hline$p: s$ & $=(111):(101)$ & 59 & 14 & 59 & 14 & 27 & $5859-59$ & 34 \\
\hline$p: p$ & $=(111):(1 \pi 1)$ & 118 & 28 & 1,18 & 28 & 16 & $118 \quad 16-118$ & 38 \\
\hline$o: r$ & $=(1+\bar{T}):(10 \bar{T})$ & 63 & 0 & 63 & 48 & 2 & $6257-63$ & 3 \\
\hline$o: 0$ & $=(1 \mid \bar{T}):(1 T T)$ & 126 & 12 & 126 & 24 & 1 & 一 & \\
\hline$c: e$ & $=(001):(311)$ & 67 & 48 & 68 & 6 & 8 & $6724-68$ & 53 \\
\hline$a: e$ & $=(100):(311)$ & 42 & $47 \frac{1}{2}$ & 42 & 38 & 0 & $4223-43$ & 31 \\
\hline$c: l$ & $=(001):(310)$ & 82 & $26 \frac{1}{2}$ & 83 & 11 & 4 & $8259-83$ & 50 \\
\hline$a: k$ & $=(100):(310)$ & 42 & 46 & 43 & 19 & 10 & $4222-43$ & 10 \\
\hline$c: f$ & $=(001):(113)$ & 39 & 9 & 39 & 7 & 7 & $3752-40$ & 59 \\
\hline$a: f$ & $=(100):(113)$ & 70 & $54 \frac{1}{2}$ & 70 & 3 & 2 & $7054-70$ & 55 \\
\hline$r: m$ & $=(10 \bar{T}):(110)$ & 78 & 20 & 78 & 17 & 12 & $785-78$ & 30 \\
\hline$r: p$ & $=(101):(111)$ & 93 & 42 & 93 & $35 \frac{1}{2}$ & 12 & $9334-93$ & 54 \\
\hline
\end{tabular}


Die Krystalle sind denen des Bromsalzes äußerlich sehr ähnlich, sie waren durchsichtig und farblos, in einer Richtung gestreckt. Die Tafelform nach der Basis war cbenfalls vorhanden, wenn auch nicht so ausgeprägt, wie beim $H B r$-Salze. Immerhin waren Basis und Querfläche meist schon durch ihre verschieden große Ausbildung von einander zu unterscheiden.

Auf dem Goniometer erwiesen sich die Krystalle als bedeutend flächenreicher als es äußerlich den Anschein hatte. In der Zone der Basis mit der Querfläche traten wie vorher wieder die beiden Schiefendflächen $s\{101\}$ und $r\{10 \bar{T}\}$ auf, und zwar ebenfalls in schmaler Form; häufig fehlten sie ganz, was namentlich für die vordere Schiefendfäche $s\{101\}$ gilt. Vollkommen ringsum ausgebildete Krystalle fehlten völlig, sie waren fast immer an einem Ende aufgewachsen und nur vereinzelt fanden sich parallele Gegenflächen zu den vorhandenen Prismen und Hemipyramiden. Von diesen Flächen fanden sich in guter Ausbildung das Verticalprisma $m\{110\}$, sowie die Hemipyramide $p\{111\}$. Außerdem traten die Hemipyramiden $o\{11 T\}, e\{311\}$ und $f\{113\}$ sowie das Verticalprisma $k\{310\}$ auf. Alle diese Flächen traten allerdings gegen die zuerst genannten an Ausdehnung stark zurück und zeigten sich nur in Form schmaler Linien mit durchweg schlechten Reflexen. Im allgemeinen waren die Flächen der Krystalle schärfer und besser ausgebildet als beim Bromsalze, weshalb auch die Signale deutlicher waren und die Messungen auf größere Genauigkeit Anspruch machen können.

Untersucht sind ganz oder teilweise vierzehn Krystalle. Am häufigsten wurde der Winkel zwischen Basis und Querfläche gemessen, der zugleich den Winkel $\beta$ darstellt und als Constante zur Berechnung verwendet wurde. Mit genügender Sicherheit konnten ferner die Winkel $a\{100\}$ zu $p\{111\}$ und $c\{001\}$ zu $p\{111\}$ festgestellt werden. Die Tabelle zeigt, daß Messung und Berechnung gut übereinstimmen.

Die Auslöschung war entsprechend dem monoklinen System auf Basis und Querfläche parallel der Combinationskante dieser beiden Flächen.

Das Bromwasserstoff- und Jodwasserstoffsalz stehen sich somit in ihrem krystallographischen Verhalten sehr nahe, wie es bei isomorphen Körpern der Fall ist, dagegen weichen sie in der Krystallform von dem Chlorwasserstoffsalze $a b$, was durch den verschiedenen Krystallwassergehalt erklärlich erscheint. Die Isomorphie der beiden erstgenannten Salze drückt sich deutlich in der großen Annäherung der Axenverbältnisse aus; auch der Winkel $\beta$ zeigt hinreichende Übereinstimmung. Ein Unterschied zwischen den Krystallen beider Substanzen zeigt sich darin, daß die des Jodwasserstoffsalzes flächenreicher sind und hier die Hemipyramide $p\{111\}$ und das Verticalprisma $m\{110\}$ hervortreten, während beim Bromwasserstoffsalze das von der Hemipyramide $p\{11 T\}$ gilt. Eine weitere Verschiedenheit. 
besteht darin, daß das Jodsalz eine deutliche Spaltbarkeit nach dem Verticalprisma $m\{110\}$ zeigte, die beim Bromsalze nicht beobachtet wurde.

Die Axenverhältnisse erscheinen in der angegebenen Form etwas ungewöhnlich, doch lag die Aufstellung, die gut ausgebildeten Flächen als primär anzunehmen, näher als die Wahl der schmalen Flächen $e$, $f$ und $k$ beim Jodwasserstoffsalze, die beim Bromwasserstoffsalze überhaupt vollkommen fehlen.

Das umgelagerte Damascenin $\mathrm{C}_{9} \mathrm{H}_{11} \mathrm{NO}_{3}+3 \mathrm{H}_{2} \mathrm{O}$.

Eine Eigentümlichkeit des zu Beginn Fig. 7. dieses Teiles erwähntèn schwer krystallisierbaren Damascenins besteht darin, daß es beim Erwärmen mit Alkalien einer molekularen Umlagerung unterworfen ist. Es

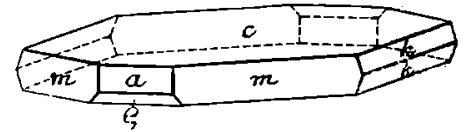
entsteht dabei eine isomere Verbindung, die im Gegensatze zum Damascenin, das basische Eigenschaften zeigt, den Charakter einer einbasischen Säure hat. Ihre Darstellung erfolgt aus salzsaurem Damascenin durch Behandlung mit Alkalien. Die so erhaltene Substanz, das umgelagerte Damascenin, krystallisiert in zwei verschiedenen Modificationen. Aus wässeriger Lösung erhält man sie in sechsseitigen Tafeln mit 3 Mol. Krystallwasser, aus absolutem Alkohol und Chloroform scheidet es sich wasserfrei in Form winziger Blättchen aus. Zur Untersuchung standen nur die wasserhaltigen Krystalle zur Verfügung.

Diese sind leicht löslich in Wasser und Alkohol, die wässerige Lösung reagiert schwach sauer; ihr Schmelzpunkt liegt bei $143^{\circ}-144^{\circ}$.

Krystallsystem : Monoklin (prismatisch).

Axenverhältnis: $a: b: c=0,8464: 1: 1,2857 ; \beta=91040^{\prime}$.

Beobachtete Formen: $a\{100\}, c\{001\}, m\{110\}, \varrho\{101\}, k\{021\}$.

Gemessen: Berechnet: Anzahl der

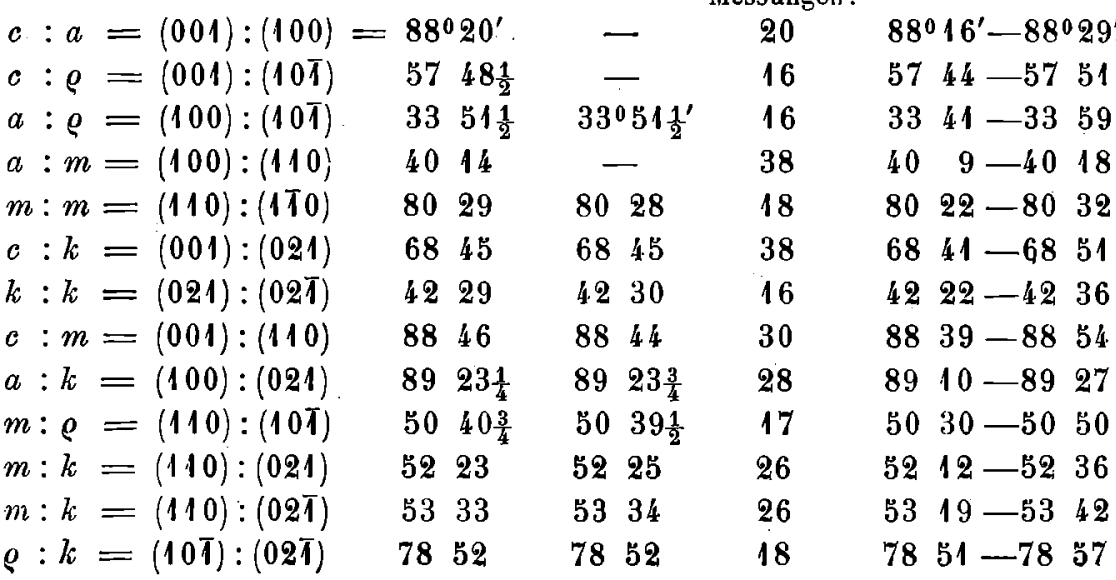


Die Größe der Krystalle beträgt $3-5 \mathrm{~mm}$, ihre Dicke etwa $2 \mathrm{~mm}$. Der Habitus ist tafelig nach der Basis mit der Regel nach sechsseitigem Umrisse. Äußerlich betrachtet, würde man sie als dem rhombischen Systeme angehörig betrachten, da der Winkel $\beta$ sowohl, als auch der zwischen Basis und Prisma $m\{1 \mid 0\}$, sowie der zwischen der Querfläche und den Klinodomen nahezu rechte sind. Die Messung ergibt indessen die Zugehörigkeit zum monoklinen Systeme.

Von Flächen wurden folgende beobachtet: am stärksten war fast immer die Basis ausgebildet, ferner war das primäre Prisma $m\{110\}$ vertreten, das in Verbindung mit dem Klinodoma $k$ den sechsseitigen Habitus bedingt. Von dem genannten Klinodoma waren fast. immer die Domen $k\{02 T\}$ und $k\{0 \overline{2} \bar{T}\}$ stärker entwickelt als die parallelen Gegenflächen. Gute Ausbildung zeigte ferner die Querfläche an einer Reihe von Krystallen, ebenso die Schiefendflächen $s\{10 T\}$ und $s\{\bar{T} 01\}$. Die obere vordere-Schiefendfläche und ihre Gegenfläche sind niemals beobachtet worden. In einigen Fällen waren die Tafeln in der Richtung der Klinoaxe gestreckt, was das Fehlen der Querfläche und der Schiefendflächen zur Folge hatte.

Eine besondere Eigenschaft, die sich beim Messen der Krystalle störend bemerkbar machte, war die, daß sie durch die Berührung mit der Luft sehr bald ihr Krystallwasser ganz oder teilweise abgaben und dadurcb ihre ursprüngliche Durchsichtigkeit verloren. Sie waren schließlich vollkommen weiß und undurchsichtig. So lange das nicht der Fall war, gaben die Krystallflächen durchweg vorzügliche Signale, die sich, wie aus der Tabelle ersichtlich ist, innerhalb sehr enger Grenzen hielten. Nach etwa einer Stunde waren die Krystalle bereits in den beschriebenen Zustand übergegangen, doch sind trotzdem die berechneten Constanten infolge der sicheren Einstellung der Signale als einwandfrei zu bezeichnen. Gemessen wurden fünfzehr Krystalle.

Die optische Untersuchung ergab, daß auf der Basis und der Querfläche die Auslöschung parallel der Combinationskante beider Flächen ist. Auf dem Prisma $m\{110\}$ betrug sie im Mittel $6^{0} 47^{\prime}$. Die Axe $b$ ist erste Mittellinie; diese steht nahezu senkrecht auf der Querfläche, auf der man im convergenten Lichte das optische Axenbild mit ziemlich großem optischem Axenwinkel sieht. Die Ebene der optischen Axen steht senkrecht zur Symmetrieebene.

Die Darstellung der Salze des umgelagerten Damascenins erfolgte in der Weise, $\mathrm{daB}$ zu einer Auflösung vón umgelagertem Damascenin eine der Säuren: $\mathrm{HCl}, \mathrm{HBr}$ und $\mathrm{HJ}$ zugesetzt wurde. Die entsprechenden Salze schieden sich dann direct aus und wurden aus wässeriger Lösung in Krystallen erhalten. 
Die Krystallformen usw. der Ephedrin-, Damascenin- und Aconitingruppe. 93

\section{Das Hydrochlorid des umgelagerten Damascenins$$
\mathrm{C}_{9} \mathrm{H}_{11} \mathrm{NO}_{3}+\mathrm{H}_{2} \mathrm{O} \text {. }
$$

Sein Schmelzpunkt liegt bei raschem Erhitzen bei 2090-2110, die Krystalle waren klar und durchsichtig, bei längerem Aufbewahren zeigten sie Verwitterungserscheinungen, indem sie weiß und durchsichtig wurden.

Krystallsystem: Triklin (pinakoidal).

Axenverhältnis :

$$
\begin{array}{ll}
a: b: c=0,66860: 1: 0,45532 . \\
\alpha=89^{\circ} 32^{\prime} 43^{\prime \prime} & A=89^{\circ} 32^{\prime} 30^{\prime \prime} \\
\beta=103360 & B=1033642 \\
\gamma=895156 & C=894830
\end{array}
$$

Fig. 8.

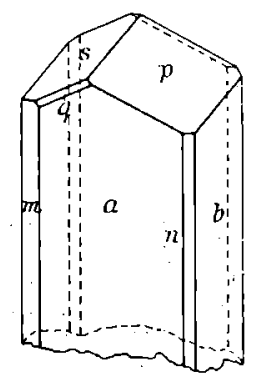

Beobachtete Formen: $a\{100\}, b\{010\}, n\{120\}, m\{1 \overline{2} 0\}, p\{0 \mid 1\}$, $s\{0 \bar{T}\}, o\left\{T_{11}\right\}$.

Gemessen: Berechnet: Anzahl der Messungen: Grenzen:

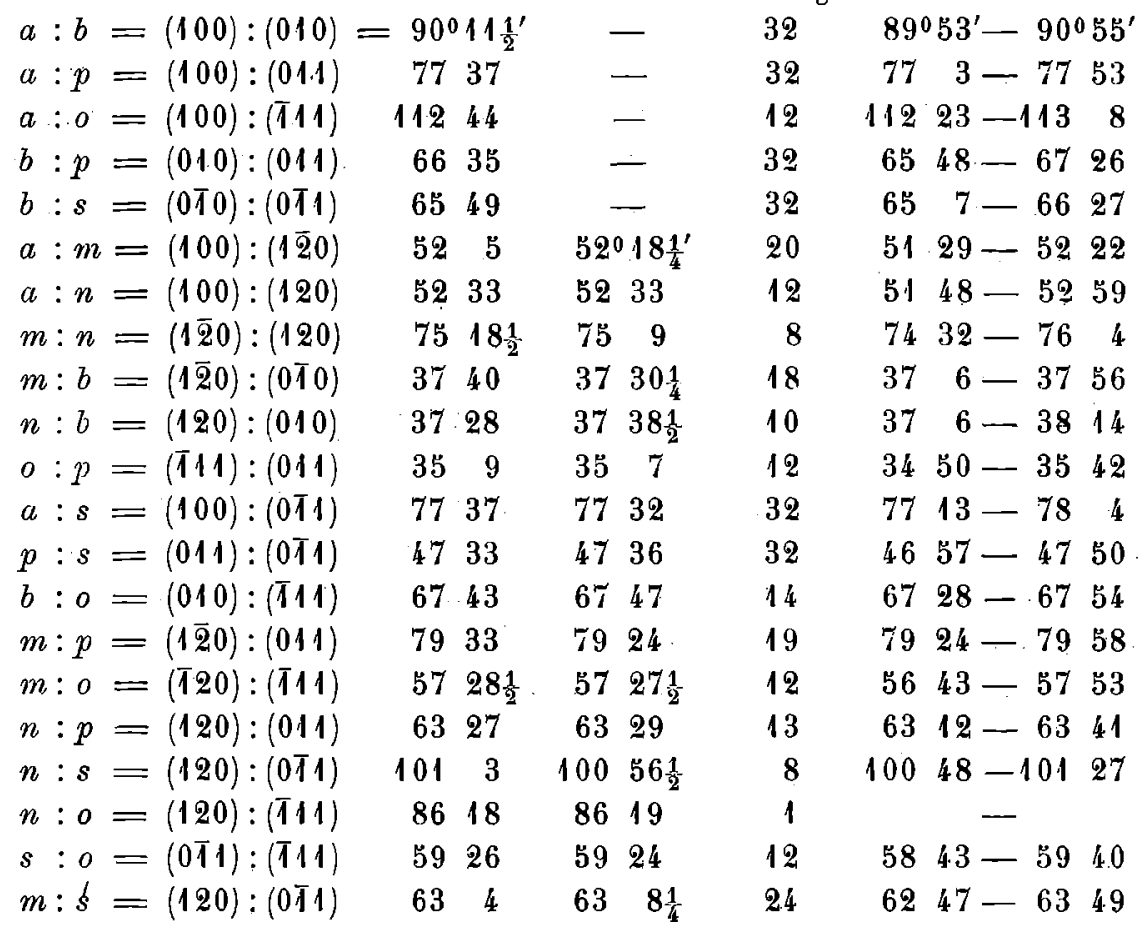

Die Krystalle waren in der Regel tafelförmig mit einer Breite von etwa $2 \mathrm{~mm}$, einer Länge von $5 \mathrm{~mm}$ und einer Dicke von $1-2 \mathrm{~mm}$ : Oft geht die Tafelform in Nadelform über. War erstere vorhanden, so wurde sie fast regelmäßig bedingt durch das Vorherrschen der Querfläche, in einem 
Falle war der Krystall tafelig nach der Längsfläche. In der Zone dieser beiden Flächen lagen ferner die beiden Verticalprismen $m\{1 \overline{2} 0\}$ und $n\{120\}$, allerdings meist, was besonders auf letzteres zutrifft, in sehr schmaler Ausbildung. Deutlicher trat in der Regel nur die eine der Prismenflächen $m$ auf. Übereinstimmend mit dem Chlorsalze des Damascenins stehen auch hier Querfläche und Längsfläche fast senkrecht auf einander, und zwar nähert sich der Winkel hier noch mehr als dort einem Rechten.

Als weitere Begrenzungsflächen traten die beiden Domen $p\{011\}$ und $s\{0 T 1\}$ auf, daneben fand sich in einigen Fällen die Viertelpyramide $o\{\bar{T} 11\}$. Alle drei Flächen waren gut ausgebildet und gaben sichere und einheitliche Signale, was im allgemeinen auch von der Quer- und Längsfläche gilt. Gemessen wurden neun Krystalle.

Die optische Untersuchung zeigte, da $\dot{B}$ die Auslöschung auf der Querfläche fast parallel war, für die Beobachtung auf der Längsfläche ergab sich als Mittel der Wert von 10012'. Die Krystalle waren nicht immer optisch homogen und zeigten zuweilen unter dem Polarisationsmikroskope ungleichmäßige Verdunkelung des Gesichtsfeldes.

An einem Krystalle war Zwillingsbildung zu beobachten; Zwillingsaxe war die Verticalaxe, Verwachsungsfläche die Querfläche. Unter dem Polarisationsmikroskope löschte das eine Individuum nach links, das andere nach rechts aus.

Die Krystalle zeigten eine vollkommene Spaltbarkeit nach $p\{011\}$ und $s\{0 T 1\}$.

\section{Das Hydrobromid des umgelagerten Damascenins $\mathrm{C}_{9} \mathrm{H}_{11} \mathrm{NO}_{3} . \mathrm{HBr}+\mathrm{H}_{2} \mathrm{O}$.}

Das Salz krystallisiert aus wässeriger Lösung mit demselben Krystallwassergehalte wie das Chlorwasserstoffsalz und verhält sich ganz dem entsprechend isomorph zu diesem. Der Schmelzpunkt der Krystalle liegt bei 2040-2060, bei längerer Aufbewahrung zeigen sie deutliche Verwitterungserscheinungen und werden trübe und undurchsichtig.

Krystallsystem: Triklin (pinakoidal).

Axenverhältnis:

$$
\begin{array}{lll}
a: b: c=0,66867: 1: 0,45670 . \\
\alpha=91030^{\prime} 7^{\prime \prime} & A=91027^{\prime} 0^{\prime \prime} \\
\beta=1023130 & B=1023115 \\
\gamma=894041 & C=8959 \quad 0
\end{array}
$$

Beobachtete Formen: $a\{100\}, b\{010\}, n\{120\}, m\{1 \overline{2} 0\}, p\{011\}$, $s\{0 T 1\}, e\{001\}, o\{(111\}, q\{1 T 1\} ; \approx\{\overline{2} 11\}$. (Vergl. Fig. 8 des isomorphen

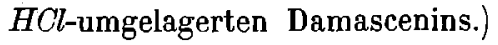


Gemessen: Berechnet: Anzahl der

\begin{tabular}{|c|c|c|c|c|c|c|c|}
\hline$a: b=(100):(010)$ & $=90^{\circ} \quad 1^{\prime}$ & - & 28 & \multicolumn{4}{|c|}{$89^{0} 25^{\prime}-90^{0} 31^{\prime}$} \\
\hline$a: p=(100):(011)$ & $78 \quad 36 \frac{1}{2}$ & 一 & 27 & 78 & $7-$ & & 18 \\
\hline$a: o=(100):(T 11)$ & 11314 & - & 20 & 112 & $58-1$ & 113 & 52 \\
\hline$b: p=(010):(011)$ & $64 \quad 45 \frac{1}{2}$ & 一 & 31 & 63 & $34-$ & & 31 \\
\hline$: s=\left(0 T_{0}\right):\left(0 T_{1}\right)$ & $6710 \frac{1}{2}$ & - & 20 & 66 & $16-$ & 68 & 23 \\
\hline$a: m=(100):(1 \overline{2} 0)$ & $5230 \frac{1}{2}$ & $52^{0} 36^{\prime}$ & 26 & 51 & $16-$ & $\check{2} 2$ & 52 \\
\hline$a: n=(100):(120)$ & $52 \quad 41 \frac{1}{2}$ & 5236 & 20 & 51 & $19-$ & 53 & 45 \\
\hline$m: n=(1 \overline{2} 0):(120)$ & $75 \quad 2$ & $74 \quad 48$ & 14 & 74 & $13-$ & & \\
\hline$m: b=(1 \overline{2} 0):(0 \bar{\top} 0)$ & $3735 \frac{1}{2}$ & 3724 & 12 & 36 & $19-$ & & 4 \\
\hline$n: b=(120):(010)$ & 3729 & 3724 & 20 & 36 & $46-$ & 38 & 44 \\
\hline$o: p=(T 11):(011)$ & $34 \quad 43 \frac{1}{4}$ & $3437 \frac{1}{2}$ & 24 & 33 & $49-$ & 35 & 10 \\
\hline$o: \approx=(T 11):(\overline{2} \mid 1)$ & $2337 \frac{1}{2}$ & 一 & 2 & 23 & $35-$ & 23 & 40 \\
\hline$a: z=(\bar{T} 00):(\overline{2} 11)$ & $4317 \frac{1}{2}$ & 一 & 2 & 43 & $12-$ & 43 & 23 \\
\hline$a: q=(100):(1 \overline{1} 1)$ & 49 & - & 4 & 49 & $4-$ & 49 & 9 \\
\hline$q: s=\left(1 T_{1}\right):\left(0 T_{1}\right)$ & $28 \quad 40$ & - & 4 & 28 & $33-$ & 29 & 1 \\
\hline$a: s=(100):(011)$ & 7753 & $78 \quad 28 \frac{1}{2}$ & 12 & 77 & $41-7$ & 78 & 8 \\
\hline$a: c=(100):(001)$ & 7654 & $77 \quad 28 \frac{3}{4}$ & 4 & 76 & $43-$ & 77 & 0 \\
\hline$b: c=(010):(001)$ & 8827 & 8833 & 6 & 87 & $14-8$ & 88 & 59 \\
\hline$s: c=(0 T 1):(001)$ & $23 \quad 59 \frac{1}{2}$ & $24 \quad 16 \frac{1}{2}$ & 5 & 23 & $12-$ & 24 & 21 \\
\hline$c: p=(001):(011)$ & 2352 & $23 \quad 47 \frac{1}{2}$ & 6 & 23 & $40-$ & 24 & 31 \\
\hline$s: p=(0 T 1):(011)$ & 484 & $48 \quad 4$ & 10 & 47 & $25-1$ & 48 & 18 \\
\hline$b: o=(010):(T 11)$ & $66 \quad 42$ & $66 \quad 26 \frac{1}{4}$ & 12 & 65 & $28-$ & 67 & 52 \\
\hline$b: q=(0 T 0):(1 T \Lambda)$ & 7258 & - & 4 & 72 & $13-7$ & 73 & 45 \\
\hline$m: q=(1 \overline{2} 0):(1 \bar{T} 1)$ & $50 \quad 43$ & - & 4 & 50 & $26-5$ & 51 & 0 \\
\hline$q: p=(1 \overline{1} 1):(011)$ & $51 \quad 47$ & $一$ & 4 & 51 & $16-5$ & 52 & 19 \\
\hline$m: p=(1 \overline{2} 0):(011)$ & $77 \quad 35 \frac{1}{2}$ & $7715 \frac{1}{2}$ & 4 & 77 & $15-7$ & 77 & 47 \\
\hline$m: s=(1 \overline{2} 0):(0 \bar{T} 1)$ & $64 \quad 6$ & $6433 \frac{1}{2}$ & 10 & 63 & $14-6$ & 65 & 3 \\
\hline$m: c=(1 \overline{2} 0):(001)$ & 83 & $8335 \frac{1}{2}$ & 2 & 82 & $56-8$ & 83 & 34 \\
\hline$m: o=(\bar{T} 20):(111)$ & 5619 & $56 \quad 8 \frac{1}{9}$ & 10 & 55 & $30-5$ & 56 & 49 \\
\hline$n: p=(120):(011)$ & $6238 \frac{1}{2}$ & $62 \quad 45 \frac{3}{4}$ & 20 & 61 & $45-6$ & 63 & 26 \\
\hline$n: c=(120):(001)$ & $8111 \frac{1}{2}$ & 8116 & 2 & 81 & $9-8$ & 81 & 14 \\
\hline$n: s=(120):(011)$ & 10024 & $100 \quad 45 \frac{3}{4}$ & 6 & 99 & $42-10$ & 00 & 56 \\
\hline$n: o=(120):(111)$ & 850 & $8531 \frac{3}{4}$. & 2 & 85 & $8-8$ & 85 & 52 \\
\hline$s: o=(0 \pi /):(T \mid 1)$ & 5938 & $59 \quad 18$ & 10 & 59 & $28-6$ & 60 & 27 \\
\hline$s: \approx=(0 \overline{1} 1):(\overline{2} 11)$ & 737 & 一 & 2 & 73 & $0 \ldots 7$ & 73 & 21 \\
\hline$c: z=(001):(\overline{2} 11)$ & 6332 & 一 & 2 & 63 & $23-6$ & 63 & 41 \\
\hline$o: c=(\overline{1} 11):(001)$ & 43 & 431 & 6 & 42 & $56-4$ & 43 & 43 \\
\hline$q: c=(1 \overline{1} 1):(001)$ & $35 \quad 8 \frac{1}{2}$ & - & 4 & 34 & $51-3$ & 35 & 28 \\
\hline$: q=(T \mid 1):(1 T 1)$ & 7823 & 一 & 4 & 78 & $2-7$ & 78 & 47 \\
\hline
\end{tabular}

Die Krystalle waren etwas kleiner als die vorigen und zeigten meist 
Tafelform, die bei den ganz kleinen Individuen zur Nadelform überging. Im Gegensatze zur Chlorwasserstoffverbindung waren hier indessen die Krystalle tafelig nach der Längsfläche oder zeigten einen quadratischen Querschnitt. Die Prismen $m\{1 \overline{2} 0\}$ und $n\{120\}$ waren in schmaler Ausbildung, aber im allgemeinen doch regelmäßiger vorhanden als vorher.

Die gewöhnlichen Endbegrenzungsflächen waren auch hier die Flächen $p\{011\}, s\{0 T 1\}$ und $o\{T 11\}$. An einem besonders flächenreichen Krystalle wurde in der Zone der Längsfläche mit $p$ und $s$ ungefähr in der Mittellage zwischen diesen beiden Flächen eine dritte gefunden, die bei der Aufstellung und Berechnung als Basis angenommen wurde. Von diesem Krystalle ist bei der Wahl der Aufstellung ausgegangen worden. Als Quer- und Längsfläche wurden die nahezu senkrecht auf einander stehenden Flächen der Hauptzone angesehen. Aus der Projection ergab sich die Annahme der Fläche $o$ als Viertelpyramide mit den Indices $o\{(11\}$. Unter Zugrundelegung der Winkel zwischen Basis, Querfläche, Längsfläche und Viertelpyramide $o\{\overline{1} 11\}$ ergab sich das Axenverhältnis

$$
a: b: c=0,65067: 1: 0,44894
$$

und daraus dann die Indices der übrigen Flächen. Unter Beibehaltung der so gefundenen Indices und Benutzung der am sichersten gemessenen Winkel konnte dann das obenstehende, wahrscheinlichere Axenverhältnis und die anderen Winkel berechnet werden.

An dem erwähnten flächenreichen Krystalle wurden außer den genannten Flächen $(p, r, s$ und o) zwei weitere Endbegrenzungsflächen constaliert, deren eine $(q)$ einerseits mit der Querfläche und dem Doma $s\{0 \overline{1} 1\}$, andererseits mit dem Doma $p\{011\}$ und dem Verticalprisma $m\{1 \overline{2} 0\}$ in eine Zone fiel. Daraus ergab sich, daB die Fläche die Viertelpyramide $q\{\mid T T\}$ sein mußte. Endlich lag in der Zone der Querfläche und dem Doma $p\{011\}$ die Viertelpyramide $\approx\{\overline{2} 11\}$. Die Flächen $c\{001\}, q\{111\}$ und $\approx\{\overline{2} \mid 1\}$ waren, wie erwähnt, nur an dem einen Krystalle zu beobachten und auch hier nur in strich- oder punktförmiger Ausbildung.

Gemessen wurden sieben Krystalle, das übrige Material war für diesen $Z_{w e c k}$ vollkommen ungeeignet. Die Signale der deutlicher ausgebildeten Flächen waren im allgemeinen genügend.

Übereinstimmend mit dem vorher beschriebenen chlorwasserstoffsauren Salze treten auch hier zwei Spaltungsrichtungen auf, und zwar verlaufen sie wie dort in Richtung der Domen $p\{011\}$ und $s\{0 T 1\}$. Der Winkel zwischen der Quer- und Längsfläche nähert sich noch mehr wie vorher einem Rechten.

Zwillingsbildung war nicht zu beobachten.

In optischer Beziehung verhält sich das Bromwasserstoffsalz ebenso 
wie das Chlorwasserstoffsalz : die Auslöschung war auf der Querfläche ganz wenig schief, auf der Längsfläche betrug sie im Mittel $10^{0} 31^{\prime}$.

Das Hydrojodid des umgelagerten Damascenins

Fig. 9.

$$
\mathrm{C}_{0} \mathrm{H}_{11} \mathrm{NO}_{3} . \mathrm{HJ}+\mathrm{H}_{2} \mathrm{O} \text {. }
$$

Der Schmelzpunkt der Krystalle liegt bei 1790, der Wassergehalt beträgt 1 Mol.

Krystallsystem: Triklin (pinakoidal).

Axenverhältnis :

$$
\begin{array}{cl}
a: b: c=0,75742: 1: 0,69457 . \\
\alpha=108^{0} 25^{\prime} 7^{\prime \prime} & A=111057^{\prime} 0^{\prime \prime} \\
\beta=1051720 & B=109250 \\
\gamma=983048 & C=104420
\end{array}
$$

\begin{tabular}{|c|c|c|c|c|}
\hline$a: b=(100):(010)=$ & $75^{01} 8^{\prime}$ & - & 39 & $74^{0} 42^{\prime}-75^{0} 49^{\prime}$ \\
\hline$a: c=(100):(001)$ & $703 \ddot{3}$ & - & 32 & $6934-71: 27$ \\
\hline$b: c=(010):(001)$ & 68 & - & 36 & $6722-69$ \\
\hline$\mu: c=\left(1 T_{0}\right):(001)$ & $8739 \frac{1}{4}$ & - & 38 & $\begin{array}{llll}87 & 9 & -88 & 37\end{array}$ \\
\hline$b: r=(0 \pi 0):(0 \pi 1)$ & 7148 & - & 2 & $7144-7152$ \\
\hline$a: \mu=(100):(1 \overline{1} 0)$ & 4314 & $420521^{\prime}$ & 40 & $4225-4426$ \\
\hline$\mu: \lambda=(1 \bar{T} 0):(1 \overline{3} 0)$ & $36 \quad 4.1 \frac{1}{2}$ & $36 \quad 42$ & 26 & $35 \quad 43-38 \quad 7$ \\
\hline$a: \lambda=(100):(1 \overline{3} 0)$ & $79 \quad 44$ & $7933 \frac{1}{2}$ & 24 & $79 \quad 15-80 \quad 35$ \\
\hline$b: \lambda=(010):(130)$ & $24 \quad 55 \frac{1}{2}$ & 20ั $8 \frac{1}{4}$ & 26 & $24 \quad 11-2538$ \\
\hline$\mu: b=(1 \bar{T} 0):(0 \bar{T} 0)$ & 6131 & $61500 \frac{1}{4}$ & 42 & $605-628$ \\
\hline$c: r=(001):(0 \pi 1)$ & 3957 & $40 \quad 9$ & 1 & 一 \\
\hline$\mu: r=(1 \bar{\Lambda} 0):(0 \bar{T} 1)$ & $68 \quad 47 \frac{1}{2}$ & $6823 \frac{1}{2}$ & 2 & $6844-6851$ \\
\hline$a: r=(\overline{1} 00):(0 T 1)$ & 9920 & 9923 & 2 & $9-9931$ \\
\hline$c: \lambda=(001):(1 \overline{3} 0)$ & 7634 & $76 \quad 26 \frac{1}{4}$ & 14 & $76.2-76 \quad 57$ \\
\hline
\end{tabular}

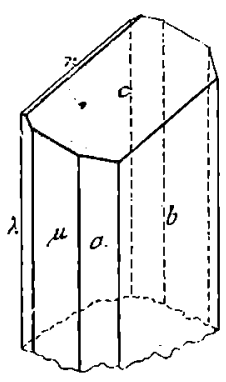

Beobachtete Formen: $a\{100\}, b\{010\}, c\{001\}, \mu\{1 \bar{T} 0\}, \lambda\{1 \overline{3} 0\}, r\{0 \bar{T}\}$.

Gemessen: Berechnet:

Anzahl der

Grenzen:

Das Salz krystallisiert in langen, dünnen, gelb gefärbten Nadeln, die sich schon äußerlich vollkommen von allen bisher beschriebenen Krystallen des Damascenins und umgelagerten Damascenins unterschieden. Mit bloßem Auge oder der Lupe konnte man die Begrenzungsflächen der Längserstreckung selten deutlich unterscheiden und auseinanderhalten. Dies war nur möglich, wenn, wie in einzelnen Fällen beobachtet wurde, die Krystalle tafelförmig waren. Dann trat neben der Fläche, deren Vorherrschen die Tafelform bedingt (Längsfläche) in guter Ausbildung noch eine zweite auf, die mit der ersten einen ziemlich stumpfen Winkel bildete. Auf dem Goniometer erschien dann zwischen beiden noch eine ganz schmale Fläche, 
die bei der Aufstellung als Querfläche angenommen wurde, während die Fläche der vorbezeichneten Lage als Verticalprisma $n\{1 \bar{T} 0\}$ festgelegt wurde.

Bei den meisten Krystallen verschwand die Tafelform dadurch, daß sich in der Längserstreckung starke Streifung geltend machte, was zur Folge hatte, daß die Krystalle gerundet erschienen. Sicher zu erkennen war dann durch die regelmäßige sehr schmale Ausbildung nur die Querfläche, nach der sich die Krystalle orientieren ließen. Die Streifung und Rundung wurde durch das wiederholte Auftreten des Verticalprismas $k\{1 \overline{3} 0\}$ und der parallelen Gegenfläche, die zwischen $b$ und $n$ fallen, hervorgerufen.

In langen Nadeln waren die Krystalle zur Messung völlig ungeeignet, da sie sich infolge der starken Streifung und Krümmung in 'der Längserstreckung schwer orientieren ließen und unbrauchbare Signale gaben. Aus diesem Grunde war die Eigenschaft der Krystalle von großem Nutzen, daß sich leicht kurze Spaltstücke herstellen ließen, die eine bequeme und sichere Messung gestatteten. Diese Spaltfläche, die an einem Krystalle parallel einer natürlichen Krystallfläche verlief, wurde als Basis angenommen. An demselben Krystalle wurde außer der Basis noch eine zweite, mit dieser und der Längsfläche in einer Zone liegende natürliche Begrenzungsfläche beobachtet, das Doma $r\{0 \bar{T}\}$. Andere Flächen als die genannten sind nicht festgestellt worden.

Sehr häufig war die Erscheinung der Zwillingsbildung zu bemerken, und zwar war Zwillings- und Verwachsungsfläche die Basis, also die Spaltfläche. Die Individuen waren so mit einander verwachsen, daß die Verticalprismen $n$, die mit der Basis fast einen rechten Winkel bilden, nahezu in eine Ebene fallen. Die $Z$ willingsbildung setzte sich häufig nach demselben Gesetze weiter zu Drillingen und Vierlingen fort. Aus diesem Grunde fand sich auch, abgesehen von dem einen erwähnten Falle, keine natürliche Ausbildung von Endflächen.

Die Messungen sind an dreizehn Krystallen vorgenommen worden und können keinen Anspruch auf besonders große Genauigkeit machen. Die Signale waren im allgemeinen schlecht und unsicher. Immerhin zeigt sich in der Berechnung der Winkel aus den Constanten eine hinreichend gute Übereinstimmung mit der Messung.

Die Schiefe der Auslöschung beträgt auf der Längsfläche $19^{\circ} 59^{\prime}$.

Infolge der guten Spaltbarkeit nach der Basis ließen sich ohne besondere Schwierigkeit dünne Blättchen herstellen, die zur genaueren optischen Untersuchung geeignet waren. Es zeigte sich, daß auf der Basis die Auslüschung fast parallel der Kante mit der Querfläche geht. Im convergenten Lichte war ein ausgezeichnetes Interferenzbild zu erhalten mit ziemlich kleinem Axenwinkel. Die optische Axenebene steht fast senkrecht auf der Querfläche. 
Die krystallographischen Beziehungen innerhalb der Damasceningruppe.

Von den Salzen des Damascenins verhalten sich das brom- und jodwasserstoffsaure Damascenin isomorph; sie sind monoklin.

$\begin{array}{lcccc} & a: b: c & \beta & \text { Schmelzpunkt: } \\ \text { Bromwasserstoffs. Damasc. } & 2,7575: 1: 2,4825 & 100^{0} \quad 6^{\prime} & 104^{0}-106^{0} \\ \text { Jodwasserstoffs. Damasc. } & 2,7519: 1: 2,4372 & 9927 & 112-115\end{array}$

Es entspricht dies auch dem gleichen Krystallwassergehalte von $2 \mathrm{Mol}$. Das abweichende, nicht jsomorphe Verhalten des chlorwasserstoffsauren Damascenins erklärt der abweichende Krystallwassergehalt, wennschon dieser an sich immerhin auffällig erscheint.

In der Reihe des umgelagerten Damascenins ist ebenso der Isomorphismus des $\mathrm{HCl}$ - und $\mathrm{HBr}$-Salzes erklärlich.

$\mathrm{HCl}$-umgelagertes Damascenin:

$$
\begin{aligned}
& \begin{array}{cllcc}
a & : b: c & \alpha & \beta & \gamma \\
0,66860 & : 1: 0,45532 & 89^{0} 32^{\prime} 43^{\prime \prime} & 103^{\circ} 36^{\prime} 0^{\prime \prime} & 89^{\circ} 51^{\prime} 56^{\prime \prime}
\end{array} \\
& A \quad B \quad C \text { Schmelzpunkt: } \\
& 89^{\circ} 32^{\prime} 30^{\prime \prime} 103^{\circ} 32^{\prime} 30^{\prime \prime} \quad 89^{\circ} 48^{\prime} 30^{\prime \prime} \quad 202^{\circ}-204^{\circ}
\end{aligned}
$$

$\mathrm{HBr}$-umgelagertes Damascenin :

$$
\begin{array}{ccccccc}
a & : b: c & & & \beta & \beta & \gamma \\
0,66867 & : 1 ; 0,45670 & 91^{\circ} 30^{\prime} & 7^{\prime \prime} & 102031^{\prime} 30^{\prime \prime} & 89^{\circ} 40^{\prime} 41^{\prime \prime} \\
A & & B & & C & \text { Schmelzpunkt: } \\
91^{\circ} 27^{\prime} 0^{\prime \prime} & 102031^{\prime} 15^{\prime \prime} & 89^{\circ} 59^{\prime} & 0^{\prime \prime} & 204^{\circ}-206^{\circ}
\end{array}
$$

$H J$-umgelagertes Damascenin :

$$
\begin{aligned}
& a: b: c \quad \alpha \quad \beta \quad \beta \quad \gamma \\
& 0,75742: 1: 0,69457 \quad 108^{0} 25^{\prime} 7^{\prime \prime} \quad 100^{0} 17^{\prime} 20^{\prime \prime} \quad 89^{\circ} 30^{\prime} 48^{\prime \prime} \\
& A \quad B \quad C \quad \text { Schmelzpunkt: } \\
& 111^{0} 57^{\prime} 0^{\prime \prime} \quad 109^{\circ} 25^{\prime} 0^{\prime \prime} \quad 104^{\circ} 42^{\prime} 0^{\prime \prime} \quad 179^{\circ}
\end{aligned}
$$

Auffallend dagegen erscheint es, daß sich das Jodwasserstoffsalz trotz des gleichen Krystallwassergehaltes als nicht isomorph mit den vorigen verhält. Hier kommt diese Verschiedenheit aber auch in dem abweichenden Schmelzpunkte zum Ausdrucke.

Eine auffallende Tatsache in der Damasceningruppe ist jedoch die weitgehende Übereinstimmung des $\mathrm{HCl}$-Damascenins mit dem $\mathrm{HCl}$-umgelagerten Damascenin.

Die Constitution der beiden isomeren Alkaloide ist nach der Mitteilung von Herrn Dr. Keller: 

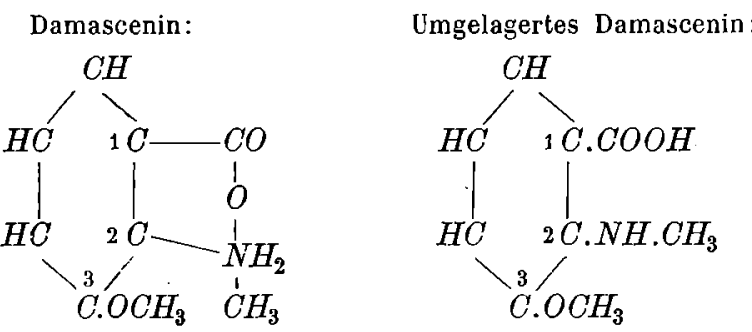

Man wird unbedingt erwarten, daß diese Verschiedenheit auch in den Chlorwasserstoffsalzen krystallographisch zum Ausdrucke kommt, wie es tatsächlich bei den $\mathrm{HBr}$-Salzen der Fall ist. Dagegen zeigt sich durch die Messungen eine nahezu absolute Übereinstimmung der beiden $\mathrm{HCl}$-Salze:

$\mathrm{HCl}$-Damascenin:

$$
\begin{array}{c:cccc}
a & : b: c & a & \beta & \gamma \\
0,66527: 1: 0,45318 & 89^{\circ} 52^{\prime} 18^{\prime \prime} & 103^{0} 30^{\prime} 52^{\prime \prime} 89^{\circ} 11^{\prime} 54^{\prime \prime} \\
A & B & C & \text { Schmelzpunkt: } \\
89^{0} 40^{\prime} 29^{\prime \prime} & 103^{\circ} 32^{\prime} 2^{\prime \prime} & 89^{\circ} 8^{\prime} 40^{\prime \prime} & 193^{0}-197^{0}
\end{array}
$$

$\mathrm{HCl}$-umgelagertes Damascenin :

$$
\begin{array}{ccccc}
a & : b: e & \alpha & \beta & \gamma \\
6860: 1: 0,45532 & 89^{\circ} 32^{\prime} 43^{\prime \prime} & 103^{\circ} 36^{\prime} 0^{\prime \prime} 89^{\circ} 51^{\prime} 56^{\prime \prime} \\
A & B & C & \text { Schmelzpunkt: } \\
89^{\circ} 32^{\prime} 30^{\prime \prime} & 103^{0} 36^{\prime} 42^{\prime \prime} & 89^{\circ} 48^{\prime} 30^{\prime \prime} & 202^{0}-204^{0}
\end{array}
$$

Die Übereinstimmung äußert sich ebenso in dem physikalischen Verhalten der Spaltbarkeit und in optischer Beziehung. Eine genauere optische Untersuchung war an dem vorhandenen Materiale nicht auszuführen, deshalb muß es auch hier unterbleiben, die Frage nach der Identität weiter zu erörtern. Auch die Krystallisationen der beiden Substanzen auf dem Objectträger verhalten sich, soweit sich beobachten ließ, unter dem Mikroskope ganz gleichartig. Es wäre aber immerhin denkbar, daß eine Verschiedenheit etwa im Sinne von rechts und links oder durch morphotrope Vertauschung der stumpfen und spitzen Axenwinkel vorliegen könnte, die hier innerhalb der Fehlergrenzen einem Rechten sich nähern, so daß der erwähnte Unterschied durch Beobachtungsfehler verschleiert sein könnte. Bedeutsam erscheint aber auch, daß das $\mathrm{HCl}$-Damascenin ganz ebenso mit 1 Mol. Wasser krystallisiert, wie die Salze der Gruppe des umgelagerten Damascenins. Jedenfalls hat aber die krystallographische Untersuchung ein wichtiges Resultat ergeben, das noch durch weitere chemische Untersuchungen zu erklären sein wird. 
Dic Krystallformen usw, der Ephedritı, Damascenin. und Aconitingruppe. 101

\section{Das Aconitin und seine Verbindungen.}

\section{Aconitin.}

Die Kenntnis des Aconitins, eines Alkaloids aus den giftigen Pflanzenarten des Genus Aconitum reicht in das Jahr 1820 zurück, in dem es durch den Genfer Apotheker Peschier aus den Blättern von Aconitum Napellus dargestellt wurde. In der Folgezeit haben sich zahlreiche Forscher mit der Darstellung und Untersuchung des Alkaloides beschäftigt. Den wesentlichsten Anteil an den Forschungen haben englische und deutsche Chemiker. Von ersteren ist besonders C. N. Alder Wright zu nennen, der für die chemische Zusammensetzung des Aconitins die Formel $\mathrm{C}_{33} \mathrm{H}_{43} \mathrm{NO}_{12}$ fand ${ }^{1}$ ). Wichtige Arbeiten rühren ferner von W. R. Dunstan und seinen Mitarbeitern her, die als Formel $\mathrm{C}_{33} \mathrm{H}_{45} \mathrm{NO}_{12}$ feststellten ${ }^{2}$ ) und den Schmelzpunkt der krystallisierten Substanz bei $188,5^{\circ}$ fanden. Zwei deutsche Chemiker, M. Freund und P. Beck, kamen zu abweichenden Resultaten, indem sie zu der Formel $C_{34} H_{47} N O_{11}$ gelangten; neben der sie die Formel $C_{34} H_{45} N O_{11}$ als möglich gelten ließen ${ }^{3}$. Den Schmelzpunkt fanden sie bei $194^{0}-195^{0}$.

Um in dieser Beziehung Klarheit zu verschaffen, hat Dr. H. Schulze sich im pharmaceutisch-chemischen Institute zu Marburg mit der Untersuchung des Aconitins beschäftigt und gefunden ${ }^{4}$ ), daß für die chemische Zusammensetzung nur die von Freund und Beck angegebenen Formeln Geltung haben können.

Diese Feststellung gab Dunstan zu der Annahme Veranlassung, daß der Unterschied der Formeln in einer Verschiedenheit der Substanzen begründet liege, mit anderen Worten, daß das englische Aconitin der Wurzel von Aconitum Napellus mit dem deutschen nicht identisch sei ${ }^{5}$ ). Obwohl diese Annahme von vornherein wenig Wahrscheinlichkeit für sich hatte, da zur Darstellung beider Substanzen dasselbe Ausgangsmaterial verwendet worden war, so war doch die chemische Untersuchung allein nicht ausreichend, zwischen der Behauptung Dunstans und der entgegengesetzten Anschauung, die auf Seiten der deutschen Forscher vertreten wurde, eine allseitig anerkannte Entscheidung herbeizuführen.

Es war daher von Wert, neben der chemischen Analyse ein weiteres Vergleichsmittel an der Hand zu haben. Ein solches war in der krystallo-

1) Journ. chem. soc. 31, I, 143 ; Compt. rend. 77, 39.

2) Ebenda 59, 231-287; Compt. rend. 91, I, 803.

3) Apothekerzeitung 1904, Nr. 79. - Archiv der Pharm. 244, 137-459 und $165-196$.

4) Ber. d. deutsch. chem. Ges. 27, I, 433-436 und 27, 720-733.

5) Journ. chem. soc. 87, 1650-1653; Compt. rend. 1905, II, 1802. 
graphischen Gegenüherstellung gegeben. Das von Dunstan dargestellte Aconitin war von Tutton gemessen worden $\left.{ }^{1}\right)$. Ebenso hatte Traube das von M. Freund und P. Beck erhaltene Aconitin krystallographisch festgelegt 2). Die Ergebnisse stimmten in jeder Beziehung überein, so daß die Identität beider Körper wahrscheinlich war. Es fragte sich, ob auch das von Dr. Schulze dargestellte Aconitin krystallographisch sich den beiden bereits gemessenen anschloß. In der Tat ergab sich, wie aus dem folgenden hervorgeht, $\mathrm{daB}$ in dieser Beziehung die Substanzen vollkommene Übereinstimmung zeigen. Die Annahme Dunstans, daß das englische und deutsche Aconitin von einander verschieden seien, dürfte damit hinfällig geworden sein.

Das von Dr. Schulze dargestellte Aconitin wurde von Diesem aus Aconitknollen durch Extraction mit Alkohol erhalten. Der Auszug wurde. eingedickt und in wässerige Lösung übergeführt. Aus dieser wurde das Alkaloid durch starke Sodalösung ausgeschieden und durch Auflösung in Methylalkohol und freiwilliges Verdunstenlassen des Lösungsmittels wurde das Aconitin amorph, durch mehrfaches Umkrystallisieren aus Methylalkohol in ganz schwach gelblich gefärbteń, gut ausgebildeten Krystallen erhalten, deren Schmelzpunkt bei $197^{\circ}$ liegt.

Es soll hier die Darstellung der vom Verfasser aus den von Dr. Schulze dargestellten Krystallen erhaltenen Resultate vorangehen und dann die Gegenüberstellung mit den Messungen der anderen Autoren folgen.

\section{Aconitin, dargestellt von Schulze.}

Krystallsystem: Rhombisch (bipyramidal).

Axenverhältnis: $a: b: c=0,54492: 1: 0,38917$.

Beobachtete Formen: $a\{100\}, p\{110\}, n\{120\}, b\{010\}, m\{101\}, o\{121\}$.

Gemessen: Berechnet:

Anzahl der

Grenzen:

\begin{tabular}{|c|c|c|c|c|c|}
\hline$: 0$ & $=(010):(121)=$ & $57039^{\prime}$ & 一 & 49 & $5702^{\prime}-58^{0} \quad 5$ \\
\hline$: m$ & $=(121):(101)$ & $3221 \frac{1}{2}$ & $32021^{\prime}$ & 36 & $\begin{array}{llll}31 & 42 & -32 & 53\end{array}$ \\
\hline$n: a$ & $=(101):(100)$ & 5428 & - & 26 & $\begin{array}{llll}54 & 4 & -54 & 49\end{array}$ \\
\hline$n: m$ & $=(101):(\overline{1} 01)$ & 716 & 714 & 22 & $7035-7134$ \\
\hline$: n$ & $=(010):(120)$ & 4223 & 4232 & 6 & $4.143-42 \quad 58$ \\
\hline$: p$ & $=(010):(110)$ & 6129 & 6125 & 19 & $\begin{array}{lll}60 & 23-62 \quad 19\end{array}$ \\
\hline$: b$ & $=(100):(010)$ & 904 & $90 \quad 0$ & 17 & $8928-91$ \\
\hline$p$ & $=(100)$ & 2828 & 2835 & 20 & $2725-2925$ \\
\hline$: n$ & $=(110$ & 1833 & 1853 & 4 & $18 \quad 10-19 \quad 16$ \\
\hline$m$ & $=(0.10):(101)$ & 8958 & $90 \quad 0$ & 14 & $\begin{array}{lll}89 & 27 & -90\end{array}$ \\
\hline
\end{tabular}

1) Journ. chem. soc. 69, 288-290; Compt. rend. 91, I, 829.

2) Ber. d. deutsch. chem, Ges. 27, 7z0-733. 
Die Krystalltormen usw. der Ephedrin-, Damascenin- und Aonnitingruppe. 103

Gemessen: Berechnel: Anzahl der Messungen: Grenzen:

\begin{tabular}{|c|c|c|c|c|c|}
\hline$n: o$ & $=(120):(121)=$ & $43^{0} 301^{\prime}$ & $43026^{\prime}$ & 11 & $43^{0} 8^{\prime}-43^{\circ}$ \\
\hline$p: o$ & $=(110):(121)$ & 4637 & $4636 \frac{1}{2}$ & 27 & $4610-47$ \\
\hline$p: m$ & $=(110):(101)$ & 5918 & $59 \quad 19$ & 10 & $5838-60$ \\
\hline$m: o$ & $=(101):(\overline{1} \overline{2} 1)$ & 74 & $5 \frac{1}{2}$ & 24 & $73 \quad 31-74$ \\
\hline$b: q$ & $=(010):(021)$ & & 52 & - & - \\
\hline$a: o$ & $=(100):(121)$ & 6033 & $6035 \frac{1}{2}$ & 16 & $5955-60$ \\
\hline$o: o$ & $=(121):(121)$ & 5852 & $58 \quad 49$ & 14 & $5825-59$ \\
\hline$o: o$ & $=(121):(1 \overline{2} 1)$ & $6438 \frac{1}{2}$ & $64 \quad 42$ & 18 & $648-65$ \\
\hline$o: o$ & $=(121):(\overline{1} \overline{2} 1)$ & $93 \quad 2$ & 938 & 16 & $92 \quad 45-93$ \\
\hline
\end{tabular}

Tutton erhielt durch seine Messungen der von Dunstan dargestellten Krystalle folgendes Resultat:

Krystallsystem: Rhombisch (bipyramidal).

Axenverhältnis:

$$
a: b: c=0,5456: 1: \mathbf{0 , 3 8 5 8 .}
$$

Beobachtete Formen: $a\{100\}, p\{110\}, n\{120\}, b\{010\}, m\{101\}$, $q\{021\}, o\{121\}$.

\section{Fig. 10.}

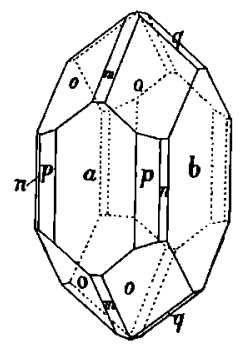

Gemessen: Berechnet: Anzahl der

Grenzen :

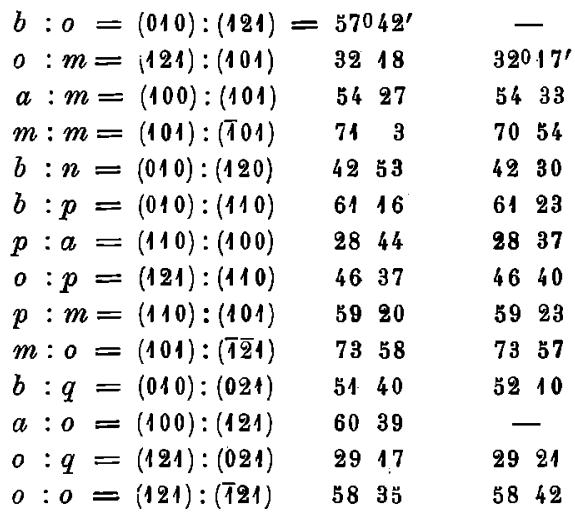

44
36
16
5
1
24
21
36
31
32
1
41
2
18

$$
\begin{aligned}
& 56036^{\prime}-58023^{\prime} \\
& 31 \quad 24-3249 \\
& 54 \quad 10-54 \quad 50 \\
& \begin{array}{lllll}
70 & 52 & -71 & 12
\end{array} \\
& 60143-62 \quad 21 \\
& 27 \quad 6-29 \quad 24 \\
& \begin{array}{llll}
46 & 4-47 & 14
\end{array} \\
& \begin{array}{llll}
58 & 41-60 & 18
\end{array} \\
& 73 \quad 4-7451 \\
& \begin{array}{lll}
59 & 32-61 & 39
\end{array} \\
& 29 \quad 3-29 \quad 30 \\
& 57 \quad 40-5924
\end{aligned}
$$

Die von Tutton gemessenen Krystalle bildeten glänzende, durchsichtige Prismen von schwach gelblicher Farbe. Die größten Krystalle waren etwa $1 \mathrm{~cm}$ lang und $0,5 \mathrm{~cm}$ dick, die meisten aber sehr klein, sogar mikroskopisch. Häufig war eine der Prismenflächen viel größer als die andere entwickelt, so daß die Krystalle manchmal tafelförmig wurden. Die Neigung zur Tafelform war auf das Vorherrschen der Längsfläche zurückzuführen.

Traube gibt von seinen Messungen der von Freund und Beck dargestellten Krystalle folgendes an: 
„Die wasserhellen, millimetergroßen Krystalle gleichen den von Tutto $n$ untersuchten; sie zeigen die Formen: $a\{100\}, b\{010\}, p\{110\}, n\{120\}$, $o\{121\}$ und $m\{101\}$, sowie bisweilen eine nicht zu bestimmende Brachypyramide, welche nur mit vier Flächen als Sphenoid auftritt.

$$
\begin{aligned}
& a: p=(100):(110)=28^{0} 56^{\prime} \text { beobachtet } \\
& b: n=(010):(120) \quad 4216 \\
& o: m=(121):(101) \quad 328 \\
& o: 0=(121):(121) \quad 5851 \\
& o: p=(121):(110) \quad 4632
\end{aligned}
$$

Auch die optischen Eigenschaften stimmen mit den von Tutton angegebenen überein «. Ein Axenverhältnis ist nicht angegeben.

Das vom Verfasser erhaltene Axenverhältnis ist unter Zugrundelegung anderer Winkel berechnet und bei näherem Vergleiche zeigt sich, daß die aus diesem Verhältnis berechneten Winkel häufig besser mit den von Tutton gemessenen übereinstimmen als die von ihm selbst berechneten, woraus auf größere Genauigkeit des vom Verfasser angegebenen Axenverhältnisses zu schließen ist.

Bezüglich der Ausbildung der Krystalle stimmen die gemachten Beobachtungen mit den von Tutton angegebenen im allgemeinen überein; die Individuen erreichten durchweg Millimetergröße. Die Längsfläche war stets sehr gut entwickelt, dasselbe gilt in den meisten Fällen von $p\{110\}$. Die Querfläche war gewöhnlich nur schmal. Stets vorhanden waren die Domen $m\{101\}$ und $m\{101\}$, von denen das eine gewöhnlich stärker ausgebildet war als das andere. Yon den vier Flächen der Pyramide o fehlte in der Regel eine oder mehrere, zuweilen traten sie nur als ganz schmale Flächen auf und wurden von $m$ ganz zurückgedrängt. Eine bestimmte Regelmäßigkeit ließ sich aber dabei nicht erkennen.

Das Verticalprisma $n$ wurde nur wenige Male in Form sehr schmaler Linien beobachtet, die Fläche $q\{021\}$ konnte mit Sicherheit nicht constatiert werden. Auch von den von Traube erwähnten Sphenoidflächen war nichts zu bemerken.

Gemessen wurden neun Krystalle. Die Reflexe müssen im allgemeinen als genügend bezeichnet werden.

Soweit eine optische Untersuchung vorgenommen werden konnte, stimmen die Ergebnisse mit denen Tuttons überein. Im convergenten Lichte erscheint auf der Querfläche das zweiaxige Interferenzbild. Die Dispersiọn ist für rotes Licht größer als für blaues.

An der krystallographischen Identität der hier gemessenen Aconitinkrystalle mit denen von Tutton gemessenen ist somit nicht zu zweifeln. Damit dürfte aber auch zugleich die Frage der chemischen Identität der beiden Substanzen im Sinne der von Schulze vertretenen Auffassung 
Die kirstallformen usw. der Ephedrin-, Danascenin und Aconitingruppe, 105

entschieden sein, denn der Nachweis der krystallographischen Identität ist zweifellos ein viel sicherer Beweis für die Richtigkeit dieser Annahme als die geringe Abweichung im Schmelzpunkte dagegen.

Es zeigt sich auch bei dieser Gelegenheit, von welcher Wichtigkeit eine genaue krystallographische Kenntnis der chemischen Körper sein kann. Deshalb war es auch von großem Interesse, Salze des Aconitins und einige andere damit zusammenhängende Verbindungen, die von Herrn Dr. Schulze dargestellt und dem Verfasser überlassen wurden, krystallographisch zu untersuchen.

$$
\begin{gathered}
\text { Aconitinhydrobromid } \\
\mathrm{C}_{34} \mathrm{H}_{47} \mathrm{NO}_{11} \cdot \mathrm{HBv}+\mathrm{2}_{\frac{1}{2}} \mathrm{H}_{2} \mathrm{O} \text {, oder } \mathrm{C}_{34} \mathrm{H}_{45} \mathrm{NO}_{11} \cdot \mathrm{HBr}+2 \frac{1}{2} \mathrm{H}_{2} \mathrm{O} .
\end{gathered}
$$

Das Salz ist dargestellt durch Neutralisation einer methylalkoholischen Lösung von Aconitin mit verdünnter Bromwasserstoffsäure. Nach Verdunsten des Fig. 11 .

Lösungsmittels und Überführung des

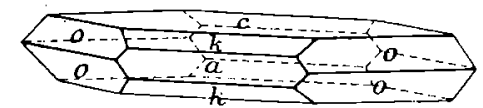

Rückstandes in eine Lösung in Alkohol und Äther erhält man eine Modification des Hydrobromids, die bei $206^{0}-2070$ schmilzt und ein Mol. Krystallwasser enthält. Aus der wässerigen Lösung dieses Salzes scheiden sich dann Krystalle ab, deren Schmelzpunkt ebenfalls bei $206^{0}-207^{0}$ liegt und die 21 Mol. Krystallwasser enthalten.

Krystallsystem: Rhombisch (bipyramidal).

Axenverhältnis: $\quad a: b: c=0,86455: 1: 1,3095$.

Beobachtete Formen: $a\{100\}, c\{001\}, k\{102\}, o\{111\}$.

Gemessen: Berechnet: Anzahl der

\begin{tabular}{|c|c|c|c|c|}
\hline$a: o=(100):(111)$ & $47025^{\prime}$ & - & 85 & $46^{0} 19^{\prime}-48^{0} 5^{\prime}$ \\
\hline$o: o=(1 \mid 1):(T \mid 1)$ & $85 \quad 16$ & $85^{0} 10^{\prime}$ & 43 & $84 \quad 10-86 \quad 32$ \\
\hline $0: 0=(111):(1 T 1)$ & 7138 & - & 26 & $76 \quad 56-72 \quad 26$ \\
\hline$o: o=(111):(11 \pi)$ & 丂 $258 \frac{1}{2}$ & 53 & 27 & $5-54 \quad 22$ \\
\hline$c: o=(001):(111)$ & 6320 & $6327 \frac{1}{2}$ & 35 & $61 \quad 19-64 \quad 34$ \\
\hline$c: k=(001):(102)$ & 一 & 378 & - & - \\
\hline$a: k=(100):(102)$ & 5236 & 5252 & 6 & $5148-5324$ \\
\hline$o: k=(111):(102)$ & 3945 & 40 & 6 & $3922-4038$ \\
\hline
\end{tabular}

Grenzen:

Die Krystalle waren $1-2 \mathrm{~mm}$ groß, rein weiß und durchscheinend. Sie waren dünntafelig nach der Basis und von sechsseitigem Umrisse. Die Basis war ferner dadurch charakterisiert, daB sie in der Richtung der Makroaxe stark gestreift war. Die Folge davon war, daß eine Messung des Winkels zwischen Basis und Querfläche einerseits und dem Doma $k$ andererseits illusorisch gemacht wurde, da man von der Basis nur eine un- 
unterbrochene Reihe von Signalen erhielt, deren Anfang und Ende etwa um 5 Grad differierten.

Die Querfläche war durchweg gut ausgebildet und gab gute und einheitliche Signale; das Makrodoma $k\{102\}$ fand sich nur an wenigen Krystallen als schmale Fläche mit schwachen Signalen. Gute Ausbildung zeigen die Pyramidenflächen, doch sind sie in der Regel in der Richtung ihrer Längsausdehnung gekrümmt, so daß die Signale bei der Messung der Zone der Pyramide mit der Basis wenig einheitlich waren und daher innerhalb ziemlich weiter Grenzen schwanken. Der Einfluß der Krümmung auf die Güte der Signale trat etwas zurück bei der Messung der beiden anderen Pyramidenwinkel, die deshalb neben dem Winkel zwischen Pyramide und Querfläche zur Bestimmung des Axenverhällnisses benutzt sind. Immerhin differieren die Grenzen um etwa zwei Grad, so daß von großer Genauigkeit auch hier nicht gesprochen werden kann. Gemessen wurden sieben Krystalle.

Die Auslöschung war auf der Basis parallel der Combinationskante mit der Querfläche.

$$
\begin{gathered}
\text { Aconitinhydrochlorid } \\
\mathrm{C}_{34} \mathrm{H}_{47} \mathrm{NO}_{11} \cdot \mathrm{HCl}+2 \frac{1}{2} \mathrm{H}_{2} \mathrm{O} \text { oder } \mathrm{C}_{34} \mathrm{H}_{45} \mathrm{NO}_{11} \cdot \mathrm{HCl}+2 \frac{1}{2} \mathrm{H}_{2} \mathrm{O} .
\end{gathered}
$$

Die Darstellungsweise entspricht der des Hydrobromids bei Anwendung von Salzsäure. Das Salz schmilzt bei 1520-1530.

Krystallsystem: Rhombisch (bipyramidal).

Axenverbältnis: $a: b: c=0,87488: 1: 1,3040$.

Beobachtete Formen: $a\{100\}, c\{001\}, k\{102\}, o\{111\}$. (Figur siehe Fig. 10 des isomorphen Aconitinhydrobromids.)

Gemessen: Berechne:

$a: o=(100):(111)=47^{0} 47 \frac{1}{2}^{\prime}$

$o: o=(111):(T 11)$

$o: o \doteq(111):(1 T 1)$

$o: o=(111):(11 T)$

$e: o=(001):(111)$

$e: k=(001):(102)$

$k: a=(102):(100)$

$c: a=(001):(100)$

$o: k=(111):(102)$
8423

720

$53 \quad 431$

$6258 \frac{1}{2}$

$36 \quad 54$

$53 \quad 2$

$89 \quad 44 \frac{1}{2}$

3958
Anzahl der

79

42

46

34

39

24

22

20

28
Grenzen:

$47^{0} \quad 5^{\prime}-48 \quad 27^{\prime}$

$\begin{array}{llll}83 & 49 & -85 & 5\end{array}$

$\begin{array}{llll}71 & 0 & -77 & 48\end{array}$

$52 \quad 9-54 \quad 15$

$\begin{array}{lll}62 & 12-63 & 57\end{array}$

$\begin{array}{llll}36 & 3-37 & 38\end{array}$

52 $19-53 \quad 55$

$\begin{array}{llll}89 & 19-90 & 53\end{array}$

$\begin{array}{lll}39 & 38-40 \quad 55\end{array}$

Die Krystalle des Hydrochlorids sind also isomorph mit denen des Hydrobromids. Sie sind ähnlich den vorhergehenden von tafeligem Habitus nach der Basis, hatten eine sechsseitige Umgrenzung und erreichten eine Größe von 1-2 mm. Sie waren rein weiß und durchsichtig. Im Vergleiche zu denen des Hydrobromids waren sie in der Regel etwas stärker, 
ferner fehlte bei ihnen die starke Streifung auf der Basis, so daß eine genauere Messung der Zone dieser Fläche mit der Querfläche und dem Makrodoma $k$ möglich war. Im allgemeinen gilt bezüglich der Flächenausbildung das bei der Beschreibung des Hydrobromids Gesagte. Die Querfläche gab die besten Reflexe; die der zwar deutlich ausgebildeten, aber stets stark gekrümmten Pyramide waren wenig einheitlich, und die Werte schwanken daher innerhalb ziemlich weiter Grenzen. Im Gegensatze zu den vorher beschriebenen Krystallen zeigten die des Hydrochlorids ein regelmäßiges Auftreten des Makrodomas $k\{102\}$, zuweilen in Form schmaler Linien, oft aber in sehr deutlicher Ausbildung.

Die Auslöschung ist, dem rhombischen Systeme entsprechend, auf der Basis und der Querfläche parallel der Combinationskante beider Flächen.

Aconitin zerfällt beim Kochen mit Wasser in Benzoesäure, Essigsäure und Aconin. Als Zwischenproduct bei dieser Umwandlung des Aconitins in Aconin entsteht

\section{Pikraconitin,}

dessen Zusammensetzung nach der Formel von Dunstan ${ }^{1)} C_{31} H_{43} N_{11}$, nach der von Freund und Beck $\left.{ }^{2}\right) \mathrm{C}_{32} \mathrm{H}_{45} \mathrm{NO}_{10}$ ist. Das Pikraconitin lag in krystallisiertem Zustande nicht zur Messung vor.

Während beim Erhitzen des Aconitins mit Wasser eine vollständige Aufspaltung der Base erfolgt, geht die Reaction beim Ersatze des Wassers durch Alkohol in etwas anderer Weise vor sich. Erhitzt man Aconitin mit Methylalkohol auf $120^{\circ}-130^{\circ}$ im geschlossenen Rohre und behandelt nach dem von Schulze angegebenen Verfahren die erhaltene Substanz weiter, indem man ihre essigsaure Lösung mit Soda ausfällt, so erhält man ein krystallinisches Product, das sich durch Umkrystallisieren aus Methylalkoholwasser in deutliche Krystalle überfübren läßt. Die Krystalle sind

$$
\begin{gathered}
\text { Methylpikraconitin } \\
\mathrm{C}_{33} \mathrm{H}_{47} \mathrm{NO}_{10} \text { oder } \mathrm{C}_{33} \mathrm{H}_{45} \mathrm{NO}_{10} .
\end{gathered}
$$

Ihr Schmelzpunkt liegt bei $210^{\circ}-211^{\circ}$.

Krystallsystem: Rhombisch (bipyramidal).

Fig. 12.

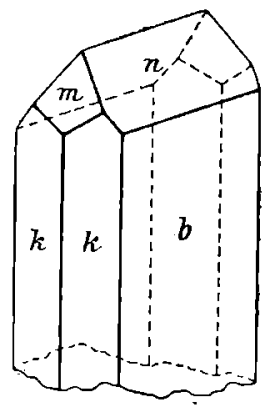

Axenverhältnis :

$$
a: b: c=0,99572: 1: 1,31416 .
$$

Beobachtete Formen: $b\{010\}, m\{101\}, n\{011\}, k\{210\}$.

i) Journ. chem. soc. 67, 459-467; Compt. rend. 95, I, 693.

2) Ber. d. deutsch. chem. Ges. 27, I, 433-436. 
k. Sehwautle.

\begin{tabular}{|c|c|c|c|c|c|c|}
\hline & & Gemessen: & Berechnel: & $\begin{array}{l}\text { Anzahl der } \\
\text { Messungen: }\end{array}$ & Grenzen: & \\
\hline$b: k$ & $=(010):(210)=$ & $=63032^{\prime}$ & — & 65 & $62013^{\prime}-64.0$ & $49^{\prime}$ \\
\hline$k: k$ & $=(210):(2 \overline{1} 0)$ & 5255 & $52^{0} 56^{\prime}$ & 30 & $5151-54$ & 1 \\
\hline$m: \not k$ & $=(101):(210)$ & 4429 & 一 & 64 & $4356-45$ & 7 \\
\hline$m: n$ & $=(101):(011)$ & 6820 & 6833 & $5 \%$ & $6753-69$ & 32 \\
\hline$n: k$ & $=(011):(210)$ & 6926 & 6914 & 50 & $6818-70$ & 4 \\
\hline$m: m$ & $=(101):(10 \overline{1})$ & $74 \quad 15$ & $74 \quad 18$ & 20 & $7324-75$ & 10 \\
\hline$m: b$ & $=(101):(010)$ & 8954 & $90 \quad 0$ & 6 & $8937-90$ & 2 \\
\hline$n: b$ & $=(011):(010)$ & 3727 & 3716 & 8 & $369-38$ & 40 \\
\hline$n: n$ & $=(011):(01 \pi)$ & 7427 & $74 \quad 32$ & 8 & $7331-75$ & 52 \\
\hline
\end{tabular}

Die klaren und durchsichtigen Krystalle waren gewöhnlich sehr klein, etwa $1 \mathrm{~mm}$ lang und hatten zum Teil noch geringere Breite. Einige besonders große Individuen erreichten eine Größe von etwa $5 \mathrm{~mm}$. Alle waren von tafeligem Habitus nach der Längsfläche, die nicht nur durch ihr Vorherrschen sofort erkennbar war, sondern auch als besonderes Merkmal eine starke Streifung in Richtung der Brachyaxe zeigte. Nur selten waren die Krystalle ringsum ausgebildet, gewöhnlich waren sie keilförmig in der Richtung der $a$-Axe zugeschärft. Diese Ausbildungsform war dadurch bedingt, daß eine der Längsflächen und eins der auf derselben Seite liegenden Domen $n\{011\}$ in einander übergingen. Mitunter war die auf diese Weise entstehende Fläche windschief gekrümmt. Da auch die Domen $n$ gewöhnlich gerundet sind, sind die Messungen der Zone dieser Flächen mit der Längsfläche sehr unsicher und unvollkommen. Nur an zwei Krystallen von den neun gemessenen waren Beobachtungen innerhalb der Fehlergrenzen möglich. Besser meßbar waren die Winkel der Prismen $k\{210\} \mathrm{zu}$ den Domen $m$ und $n$ und die Domenwinkel unter einander.

Die Signale sind im Durchschnitte als genügend zu bezeichnen, die besten Ergebnisse lieferten die Messungen der kleineren Individuen.

Die Auslöschung ist auf der Längsfläche parallel der Combinationskante mit den Domen $n$.

Äthylpikraconitin $\mathrm{C}_{34} \mathrm{H}_{49} \mathrm{NO}_{10}$ oder $\mathrm{C}_{34} \mathrm{H}_{47} \mathrm{NO}_{10}$.

Fig. 13.

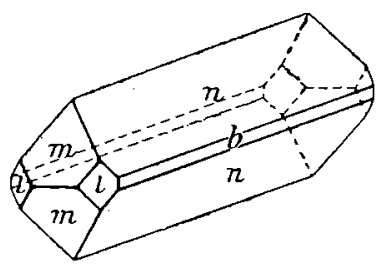

Die Darstellung dieser Base erfolgte in ähnlicher Weise wie die des Methylpikraconitins durch Erhitzen von Aconitin mit absolutem Äthylalkohol. Die Krystallisation gelingt nur nach dem besonderen, von Schulze ausgearbeiteten Verfahren. Die zur Untersuchung verwendeten Krystalle sind auf diese Weise aus Methylalkohol durch Umkrystallisierung er-

halten. Ihr Schmelzpunkt liegt bei $1 \mathbf{8 8}^{\circ}$. 
Krystallsystem: Rhombisch (bipyramidal).

Axenverhältnis: $\quad a: b: c=0,97952: 1: 1,2700$.

Beobachtete Formen: $b\{010\}, m\{101\}, n\{011\}, l\{110\}$.

$$
\text { Gemessen: Berechnet: Anzahl der }
$$

Grenzen:

$\begin{array}{lllllllr}m: m=(101):(10 \bar{\jmath})=75017^{\prime} & - & 36 & & 74^{0} 44^{\prime}-75046^{\prime} \\ m: n=(101):(011) & 6748 & - & 78 & & 67 & 14-68 & 34 \\ n: n=(011):(01 \overline{1}) & 7623 \frac{1}{2} & 76^{0} 26^{\prime} & 18 & & 76 & 6-77 & 4 \\ n: b=(011):(010) & 3812 & 3813 & 8 & & 37 & 21-39 & 36 \\ m: l=(101):(110) & 5530 & 5533 & 30 & & 54 & 49-55 & 43 \\ n: l=(011):(110) & 5635 & 5639 & 31 & 56 & 5-57 & 1 \\ l: l=(110):(110) & 8839 & 8849 & 9 & 88 & 21-89 & 17 \\ l: b=(110):(010) & 4539 & 4535 \frac{1}{2} & 11 & 45 & 17-46 & 3 \\ m: b=(101):(010) & 8945 & 90 & 0 & 8 & 88 & 53-90 & 34\end{array}$

Die Krystalle waren klar und durchsichtig, ihre Größe betrug 1-2 mm. Sie waren durchweg ziemlich flächenarm, doch von guter Ausbildung. Die Aufstellung und Flächenbezeichnung ist mit Rücksicht auf den Vergleich mit dem Methylpikraconitin diesem entsprechend gewählt worden.

Der Habitus der Krystalle ist vollkommen verschieden von dem der Methylverbindung. Die Individuen stellen fast durchweg eine Combination des primären Brachydomas $n\{011\}$ und des primären Makrodomas $m\{101\}$ dar und zeigen bei guter Ausbildung dieser Flächen gewöhnlich eine Längserstreckung in Richtung der Brachyaxe. In einem Falle war eine Verzerrung der normalen Krystallform zu constatieren.

Gemessen worden sind zehn Krystalle. Zur Berechnung des Axenverhältnisses wurden die beiden am häufigsten gemessenen Winkel benutzt. Die Festlegung des Winkels zwischen den Brachydomen war insofern etwas unsicher, als sich zuweilen eine leichte Krümmung dieser Flächen bemerkbar machte, die störend auf die Güte der Signale einwirkte. Gut und häufig meßbar war dagegen der Winkel, den die beiden Domen $m$ und $n$ einschlieBen.

In Verbindung mit den beiden Domen trat gewöhnlich das Verticalprisma $l\{110\}$ auf, allerdings in der Regel nur mit einer oder zwei Flächen, die in Form von kleinen Quadraten die Ecken abstumpfen. Nur an dem erwähnten verzerrten Krystalle waren sie vorherrschend. Die Längsfläche wurde nur in einigen Fällen beobachtet und auch hier nur in Form schmaler Linien. Andere als die genannten Flächen waren nicht zu bemerken.

Die Signale waren im allgemeinen genügend sicher, so daß die Berechnung der Constanten Anspruch auf Genaugkeit machen kann. 
Die krystallographischen Beziehungen zwischen Methyl- und Äthylpikraconitin.

Die vorstehenden Untersuchungen liefern einen Beitrag zur Kenntnis der morphotropischen Wirkung bei der gegenseitigen Verttretung der Methylund Äthylgruppe. Es wird sich hier um die Frage handeln, ob wir die beiden Verbindungen noch als isomorph bezeichnen künnen oder nicht. Da isomorphe Mischungen beider Körper nicht vorlagen und auch eine genaue optische Bestimmung des Materials ausgeschlossen war, müssen wir uns auf den krystallographischen Vergleich beschränken. Hier zeigt sich nun, daß mit dem Ersatze der einen Gruppe durch die andere eine im Vergleiche zu isomorphen Körpern ziemlich beträchtliche Änderung des Axenverhältnisses stattfindet. Allerdings erstreckt sich die Änderung auf das ganze Axenverhältnis und nicht, wie es in besonders markanten Fällen morphotropischer Änderung der Fall ist, wesentlich nach einer bestimmten Richtung. Andererseits ist aber auch der Krystallhabitus der beiden Substanzen verschieden, was seinen besonderen Ausdruck darin findet, daß beim Methylpikraconitin das Verticalprisma $k\{210\}$, dagegen beim Äthylpikraconitin das Prisma $l\{110\}$ auftritt. Aus diesem Grunde ist es vielleicht besser von Morphotropie als von Isomorphie zu sprechen.

Wie erwähnt, ist das Pikraconitin eine Zwischenstufe bei der Umwandlung des Aconitins in Aconin, die beim Erhitzen des ersteren vor sich geht. Aconin entsteht ferner bei der Verseifung von Pikraconitin mit alkoholischer Kalilauge. Es ist eine Base, die im freien Zustande ein weilbes, lockeres, ziemlich hygroskopisches Pulver darstellt. Krystallisiert konnte sie nicht erhalten werden, dagegen bilden verschiedene ihrer Salze Krystalle. Von diesen lag das Aconinhydrochlorid zur Untersuchung vor.

Aconinhydrochlorid $\mathrm{C}_{25} \mathrm{H}_{41} \mathrm{NO}_{9} \cdot \mathrm{HCl}+2 \mathrm{H}_{2} \mathrm{O}$.

Fig. 14.

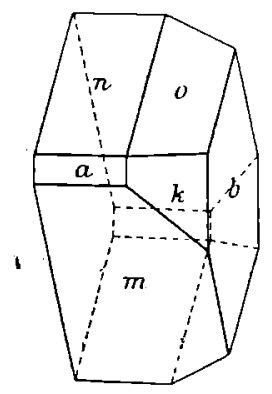
durch Erhitzen auf $160^{\circ}-170^{\circ}$ und Behandeln mit Salzsäure. Nach der Reinigung von der dabei entstehenden Benzoësäure wurden die Krystalle aus wässeriger Lösung erhalten. Das Alkaloid ist leicht löslich in Wasser und Alkohol, sein Schmelzpunkt liegt bei $176, \mathbf{5}^{0}$.

Krystallsystem: Monoklin hemimorph (sphenoidisch).

Axenverhältnis :

$$
a: b: c=0,63461: 1: 1,0374 ; \beta=90^{\circ} .
$$

Beobachtete Formen: $a\{100\}, b\{010\}, m\{10 \pi\}, n\{101\}, k\{110\}$, $o\{111\}$; außerdem in besonderen Fällen: $\alpha\{230\}, \omega\{233\}$. 
Die Krystallformen usw. der Ephedrin-, Damascenin- und Aconitingruppe. 111

\begin{tabular}{|c|c|c|c|c|c|c|}
\hline & Gemessen: & Berechnet: & $\begin{array}{l}\text { Anzahl der } \\
\text { Messungen: }\end{array}$ & & Grenzen: & \\
\hline$a: n=(100):(101)$ & $=32^{0} 25^{\prime}$ & - & 15 & 320 & $05^{\prime}-33^{0}$ & $0^{\prime}$ \\
\hline$n: m=(101):(10 \overline{1})$ & $64 \quad 48$ & $64^{0} 50^{\prime}$ & 26 & 64 & $2-65$ & 36 \\
\hline$b: n=(010):(10.1)$ & 8958 & 90 & 26 & 88 & $57-91$ & 4 \\
\hline$b: o=(010):(111)$ & $6236 \frac{1}{2}$ & 6241 & 26 & 62 & $0-63$ & \\
\hline$n: o=(101):(111)$ & $27 \quad 19$ & 一 & 28 & 26 & $52-28$ & 12 \\
\hline$o: o=(111):(\bar{T} 1 \mathrm{~T})$ & $54 \quad 46$ & $54 \quad 39$ & 7 & 54 & $6-55$ & 41 \\
\hline$a: o=(100):(111)$ & 4151 & 4124 & 0 & 40 & $33-42$ & 4.2 \\
\hline$m: o=(10 \overline{1}):(111)$ & 748 & 1. 46 & & 67 & $2-68$ & 29 \\
\hline$b: k=(010):(110)$ & 5728 & 833 & 11 & 56 & $32-56$ & 39 \\
\hline$a: b=1100$ & 8943 & 90 & 30 & 88 & $59-90$ & 43 \\
\hline$o: k=(111):(110)$ & 285 & $28 \quad 26$ & 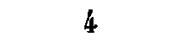 & 27 & $20-28$ & 51 \\
\hline$k: o=(110):(\bar{T} 1 \bar{T})$ & $111 \quad 42$ & 11337 & 3 & 109 & $34-114$ & 34 \\
\hline
\end{tabular}

Die im Durchschnitte etwa 3:2:1 mm großen Krystalle zeigten in ihrer typischen Form dicktafelige rhombische Gestalt von der Combination eines stumpfen rhombischen Prismas mit Basis, Pyramide und untergeordnet Brachydoma und seltener und schmäler der Querfläche. Charakteristisch ist aber, daß die Pyramidenflächen an allen zehn gemessenen Krystallen dieser Ausbildung nur in zwei Stellungen gemeinsam auftreten, die nach dieser rhombischen Auffassung der Lage (1T1) und (T11) entsprechen würden. Eine solche Combination ist, da sie an allen zehn Krystallen mit vollkommener Regelmäßigkeit auftritt, mit der Annahme einer rhombischen Symmetrieklasse unvereinbar. Die Krystalle müssen deshalb der monoklinhemimorphen Klasse angehören, entsprechend der oben angegebenen Aufstellung. Es bleiben dann die gemessenen rechten Winkel bestehen und der monokline Charakter könnte sich nur in der Verschiedenheit der Winkel $m: k$ und $n: k$ oder $m: a: n$ äußern. Die Unterschiede liegen aber bei der Unvollkommenheit der Signale und den Abweichungen der Winkel der entsprechenden Flächenlage vollkommen im Bereiche der Fehlergrenzen, so $\mathrm{da} \beta$ auf die Berechnung des Winkels $\beta$ verzichtet und die. Berechnung der Flächenwinkel nach dem rhombischen Axensysteme vorgenommen werden mußte.

An verschiedenen Krystallen zeigten sich Blätterbrüche entsprechend den Flächen $k$, was sich auch künstlich durch Erzeugung von Spaltflächen bestätigen ließ. Aber auch für die Messungen zu diesen nicht sehr vollkommenen Spaltflächen gilt das eben Gesagte. Eine zweite Spaltbarkeit wird durch Blätterbrüche angedeutet, die an einem Krystalle auf der Fläche $n$ parallel der Kante $o / n$ verlaufen.

Auffallenderweise zeigt auch das optische Verhalten keine Abweichungen, die gegen das rhombische System sprechen würden. Die Auslüschung geht auf $m$ und $n$ der Kante $m / n$ (und den eben erwähnten 
Spaltrissen) parallel, was auch nach der monoklinen Auffassung gefordert wird.

Dagegen geht auch auf $b\{010\}$ die Auslöschung in allen Fällen den Spaltrissen nach $k$ parallel. Im convergenten polarisierten Lichte sieht man durch $n$ das Bild einer Axe austreten. Die Ebene der optischen Axen liegt parallel der Fläche $b\{010\}$.

Von den beschriebenen Krystallen der typischen Ausbildung wichen einige Krystalle in ihrer Form vollkommen ab. An einem Krystalle (Nr. 11) fehlen von der vorher beschriebenen Combination die Flächen $m$ und $n$, dafür sind $o_{1}=\{111\}$ und $\{T 1 T\}$ entsprechend stärker entwickelt und an Stelle von $n$ treten auf $o_{2}=\{1 T T\}$ und $\{T T 1\}$, wodurch der Krystall einen rhombisch-bisphenoïdischen Habitus erhält. Die gemessenen Winkel sind im Vergleiche mit den aus obigem rhombischen Axenverhältnise berechneten wie folgt erhalten:

$$
\begin{array}{lll}
\text { Gemessen: } & \text { Berechnet: } \\
b: o_{2}=(0 T 0):(1 T T)=61^{0} 39^{\prime} & 62^{0} 41^{\prime} \\
o_{1}: o_{2}=(111):(1 T T) & 9628 & 9712 \\
o_{1}: o_{2}=(\bar{T} T \bar{T}):(1 T T) & 5611 & 5652
\end{array}
$$

Die Abweichungen von den rhombischen Werten liegen auch hier derart innerhalb der Fehlergrenzen, daß eine Berechnung monokliner Constanten keine zuverlässigen Werte liefern würde.

Im Gegensatze zu den vorher beschriebenen Krystallen zeigen fünf Individuen einen holoëdrischen Habitus durch Auftreten der Pyramidenflächen in allen acht Stellungen. Die Flächen $m$ und $n$ erscheinen nur als schmale Abstumpfungen der Kanten der Pyramiden. Die Krystalle sind zugleich etwas gestreckt nach der $c$-Axe (der Kante $k / b$ ).

Ganz besonders auffallend ist aber, daß an allen Krystallen dieser Art noch weitere Flächen auftreten und zwar bemerkt man zwischen $k$ und $b$ noch eine Fläche $\alpha$ und außerdem weitere Pyramidenflächen $\omega$ in der Zone $[\alpha, o]$ über o hinaus und zugleich in der Zone $[\alpha, 001]$. Die Lage von $\alpha$ entspricht ungefähr einer Fläche

$$
\begin{gathered}
\{230\}=\frac{3}{2} a: b: \infty c \\
\text { dann ist } \omega=\{233\}=\frac{3}{2} a: b: c=0,95191: 1,0374: 1 .
\end{gathered}
$$

Wir sehen also in dem Auftreten dieser Flächen das Bestreben der Krystalle die Axe $a$ den beiden anderen, die schon unter sich fast übereinstimmen, möglichst gleich zu machen.

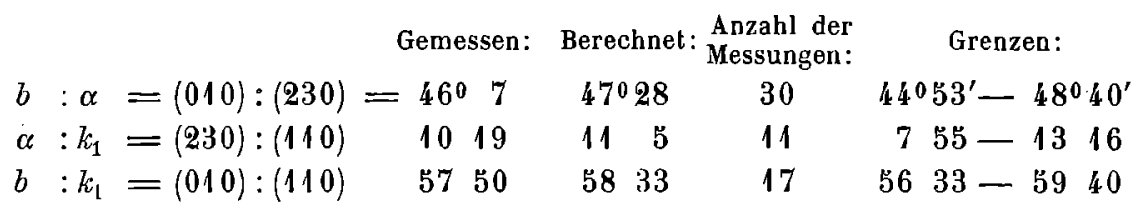


Die Ḱrystallormen usw. der Ephedrin-, Damascenin- und Aconitingruppe. 113

\begin{tabular}{|c|c|c|c|c|c|c|}
\hline & & Gemesse & Berecht & $\begin{array}{l}\text { Anzahl der } \\
\text { Messungen: }\end{array}$ & & Grenzen: \\
\hline$\alpha$ & $: \alpha=(230):(2 \overline{3} 0)$ & $==8703^{\prime}$ & $850 \quad 4^{\prime}$ & 9 & $84^{0}$ & $04^{\prime}-89^{\circ} 14^{\prime}$ \\
\hline$b$ & $: o_{1}=(010):(1+1)$ & 6155 & 6241 & 54 & 60 & $2-6340$ \\
\hline$n$ & $: o_{1}=(101):(111)$ & 2710 & 27 & $3 \check{~}$ & 20 & $30-2951$ \\
\hline$o_{1}$ & $: o_{2}=(111):(11 \pi)$ & 5651 & 5439 & 16 & 54 & $52-5826$ \\
\hline$b$ & $: n=(010):(101)$ & 9021 & 90 & 28 & 88 & $22-91$ \\
\hline$b$ & $: \omega_{1}=(010):(233)$ & 5635 & 5623 & 31 & 54 & $\breve{2} 2-5930$ \\
\hline & $: o_{1}=(233):(111)$ & 950 & 1130 & 7 & 7 & $29-13$ \\
\hline$n$ & $: \omega=(101):(233)$ & 3333 & 3513 & 4 & 33 & $0-3418$ \\
\hline & $: k_{1}=(111):(110)$ & 2821 & 2826 . & 19 & 27 & $6-2952$ \\
\hline & $: o_{4}=(T \mid T):(\Lambda T T)$ & 5617 & $56 \quad 52$ & 10 & 55 & $1-5724$ \\
\hline$\alpha$ & $: \omega_{1}=(230):(233)$ & $34 \quad 15$ & 35 & 15 & 33 & $5-3449$ \\
\hline & $: \omega_{2}=(10 \bar{T}):(23 \overline{3})$ & $34 \quad 44$ & $35 \quad 13$ & 4 & 33 & $32-3551$ \\
\hline & $\therefore \omega_{2}=(2 \overline{3} 3):(\overline{2} \overline{3} 3)$ & 11246 & 11246 & 3 & 112 & $18-1130$ \\
\hline 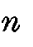 & $: m=(101):(10 \overline{1})$ & 6456 & 6450 & 16 & 64 & $2-6546$ \\
\hline$\omega_{1}$ & $: k_{1}=(233):(110)$ & $3556 \frac{1}{2}$ & 3633 & $\ddot{z}$ & 34 & $26-36 \quad 17$ \\
\hline$n$ & $: \alpha=(101):(230)$ & 5138 & $51 \quad 32$ & 12 & 50 & $11-5256$ \\
\hline 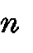 & $: k_{1}=(101):(110)$ & $44 \quad 18$ & 446 & 10 & 43 & $13-4521$ \\
\hline$\alpha$ & $: o_{1}=(230):(111)$ & 30 & 3020 & 24 & 28 & $18-3120$ \\
\hline
\end{tabular}

Die vorstehende Tabelle enthält eine Zusammenstellung der an den Krystallen mit boloëdrischem Habitus gemessenen Winkel mit den berechneten, wobei für $\alpha$ und $\omega$ die Indices $\{230\}$ und $\{233\}$ angenommen sind. Wir beobachten hier ein erhebliches Schwanken der Flächenwinkel. Die gemessenen Winkel zeigen noch mehr das Bestreben eine Flächenlage $a=b=c$ zu erreichen. Die Werte von $\alpha: \alpha$ nähern sich ebenso dem berechneten Winkel von $85^{\circ} 4^{\prime}$ wie dem regulären von $90^{\circ}$.

Da wir die zuerst beschriebenen zehn Krystalle durchaus als die normalen betrachten müssen, werden.wir die Krystalle von holoëdrischem Habitus als Ergänzungszwillinge, und zwar als Zwillinge der Combination des mit Nr. 11 bezeichneten Krystalles nach $\{010\}$ auffassen müssen, In dieser Zwillinsgbildung werden wir dann auch die Ursache für das Auftreten der Flïchen $a$ und $\omega$ sehen künnen.

Das optische Verhalten ist derart, daß sich Schnitte durch die Kry. stalle (Spaltblättchen nach $k$ ) vollkommen homogen wie die einfachen Krystalle verhalten, wenigstens stets in ihrem Kerne. Die Randzone zeigt zwischen gekreuzten Nicols bei der Dunkelstellung polarisierende Flimmerchen wie Einschlüsse kleiner abweichend orientierter Partikel. 


\section{Zusammenfassung der Ergebnisse.}

1) Die Arbeit enthält die krystallographische Untersuchung der Verbindungen der Ephedrin-, Damascenin- und Aconitingruppe.

2a) Es wurde nachgewiesen, daß das durch Umlagerung aus Ephedrin dargestellte Pseudoephedrin mit der als natürliche Base erhaltenen Substanz krystallographisch vollkommen identisch ist.

2b) Das Pseudoephedrin liefert ein ausgezeichnetes Beispiel für sehr vollkommen biegsame Krystalle.

2c) Die Verschiedenheit der beiden isomeren Alkaloide zeigt sich auch in der Krystallform ihrer Verbindungen und ist auch in den Methylverbindungeh nicht durch die Methylierung aufgehoben.

2d) Die krystallographische Untersuchung lieferte ein neues Charakteristikum für die Unterscheidung der Ephedrin- und Pseudoephedrinverbindungen, das in der Hemiëdrie der ersteren gegenüber der Holoëdrie der letzteren besteht und für die Erklärung der Structur von Wichtigkeit sein kann.

3 a) In der Damasceninreihe sind das $H B r$ - und $H J$-Salz isomorph, dagegen nicht mit diesen das $\mathrm{HCl}$-Salz, das auch mit abweichendem Krystallwasser krystallisiert. In der Reihe des umgelagerten Damascenins zeigt sich Isomorphie zwischen dem $\mathrm{HCl}$ - und $\mathrm{HBr}$-Salze, dagegen weicht trotz des gleichen Krystallwassers das $H J$-Salz von diesem ab.

3b) Eine ganz auffallende Übereinstimmung zeigt sich zwischen dem $\mathrm{HCl}$-Damascenin und dem $\mathrm{HCl}$-umgelagerten Damascenin, die bei der chemischen Verschiedenheit der beiden Isomeren schwer verständlich erscheint. Die Frage nach der Identität oder der Art der Verschiedenheit ließ sich nicht vollkommen entscheiden, aber die krystallographische Untersuchung hat hier für die weitere chemische Untersuchung ein wichtiges Resultat ergeben.

4a) Durch den Nachweis der krystallographischen Identität des englischen und deutschen Aconitins konnte die Streitfrage nach der Identität der Substanzen, die durch chemische Untersuchungen nicht einwandfrei zu beweisen war, endgültig entschieden werden.

4b) Die $\mathrm{HCl}$ - und $\mathrm{HBr}$-Salze des Aconitins sind isomorph.

4c) Die krystallographische Untersuchung des Methyl- und Äthylpikraconitins liefert einen Beitrag zur Kenntnis der morphotropischen Wirkung der Methyl- und Äthylgruppe.

4) Die Krystalle des Aconinchlorhydrats ergaben nach den Winkeln ein Axensystem, das einer rhombischen Klasse entsprechen würde; auch die optischen Beobachtungen entsprechen durchaus dem rhombischen 
Die Krystallformen usw. der Ephedrin-, Damascenin- und Aconilingruppe. 115

Systeme, dagegen zeigen die normal ausgebildeten Krystalle eine Symmetrie, die einer teilflächigen Klasse dieses Systems nicht genügt. Sie müssen daher der monoklin-hemimorphen Klasse zugerechnet werden.

4.e) Bei den Ergänzungszwillingen zeigt nicht nur der Habitus scheinbar rhombisch-holoëdrische Krystalle, sondern zugleich ist das Auftreten von Flächen zu beobachten, die eine reguläre Axenlage mit drei gleichen Axen zu erreichen suchen.

5) Auch die vorliegende Arbeit, insbesondere in den Fällen 2c, 3b und 4a, hat erneut bewiesen, daß die krystallographische Untersuchung der chemisch dargestellten Körper nicht nur von dem größten Interesse, sondern für eine vollständige Kenntnis der Substanzen auch notwendig ist. 